\title{
Defining function of wild-type and patient specific TP53 mutations in a zebrafish model of embryonal rhabdomyosarcoma
}

Jiangfei Chen ${ }^{\star 1,2}$, Kunal Baxi²,3, Amanda E. Lipsitt ${ }^{2,4}$, Nicole R. Hensch ${ }^{2,3}$, Long Wang ${ }^{2,3}$, Antoine Baudin ${ }^{2,5}$,

Daniel G. Robledo², Abhik Bandyopadhyay², Aaron Sugalski ${ }^{4}$, Anil K. Challa², Andrea R. Gilbert ${ }^{6}$, Gail E.

Tomlinson ${ }^{2,4}$, Peter Houghton ${ }^{2,3}$, Eleanor Y. Chen ${ }^{7}$, David S. Libich ${ }^{2,5}$ and Myron S. Ignatius ${ }^{2,3 \dagger}$.

${ }^{1}$ Institute of Environmental Safety and Human Health, Wenzhou Medical University, Wenzhou, 325035, PR China

${ }^{2}$ Greehey Children's Cancer Research Institute (GCCRI), UT Health Sciences Center, San Antonio, Texas, 78229, USA

${ }^{3}$ Department of Molecular Medicine, UT Health Sciences Center, San Antonio, Texas, 78229, USA

${ }^{4}$ Department of Pediatrics, Division of Hematology Oncology, UT Health Sciences Center, San Antonio, Texas, 78229, USA

${ }^{5}$ Department of Biochemistry and Structural Biology, UT Health Sciences Center, San Antonio, Texas, 78229, USA

${ }^{6}$ Department of Pathology and Laboratory Medicine, UT Health Sciences Center, San Antonio, Texas, 78229, USA

${ }^{7}$ Department of Laboratory Medicine and Pathology, University of Washington, Seattle, WA 98195, USA

* Equal Contribution

†Senior and corresponding author

Myron Ignatius, PhD, ignatius@uthscsa.edu

Journal: eLIFE

Publication type: Research Article 
bioRxiv preprint doi: https://doi.org/10.1101/2021.04.21.440757; this version posted April 22, 2021. The copyright holder for this preprint (which

was not certified by peer review) is the author/funder, who has granted bioRxiv a license to display the preprint in perpetuity. It is made available under aCC-BY 4.0 International license.

\section{Abstract (150 words)}

In embryonal rhabdomyosarcoma (ERMS) and generally in sarcomas, the role of wild-type and loss or gain of function TP53 mutations remains largely undefined. Eliminating mutant or restoring wild-type p53 is challenging; nevertheless, understanding TP53 effects on tumorigenesis remains central to realizing better treatment outcomes. In ERMS, >70\% of patients retain wild-type TP53, yet TP53 mutations when present in tumors are associated with poor prognosis. Employing a $k R A S^{G 12 D}$-driven ERMS tumor model and newly generated tp53 null $\left(\operatorname{tp} 53^{-/-}\right)$zebrafish, we define both wild-type and patient-specific TP53 mutant effects on tumorigenesis. We demonstrate that $t p 53$ is a major suppressor of tumor initiation, where tp53 loss expands tumors initiation from $<35 \%$ to $>97 \%$ of animals. Next, characterizing three patient-specific mutants finds that TP53 ${ }^{C 176 F}$ partially retains wild-type p53 apoptotic activity that can be exploited, while the TP53 ${ }^{P 1534}$ and TP53 ${ }^{\mathrm{Y} 220 C}$ mutants define two structural mutations that predispose to head musculature ERMS. 
bioRxiv preprint doi: https://doi.org/10.1101/2021.04.21.440757; this version posted April 22, 2021. The copyright holder for this preprint (which

was not certified by peer review) is the author/funder, who has granted bioRxiv a license to display the preprint in perpetuity. It is made available under aCC-BY 4.0 International license.

\section{Introduction}

TP53 is the best-known tumor suppressor protein that is mutated or functionally disrupted in more than $50 \%$ of human tumors (Kastenhuber \& Lowe, 2017; Muller \& Vousden, 2014). Germline mutations in TP53 are responsible for Li-Fraumeni Syndrome that predisposes to a wide but distinct spectrum of tumors that change with age (Malkin, 2011). Comprehensive analyses of TP53 function in vivo and in vitro have revealed three different ways by which TP53 can modulate tumorigenesis. These include effects caused by loss-of-function mutations, gain-of-function mutations, or dominant-negative mutations that disrupt the function of wild-type protein (Ko \& Prives, 1996; Levine, Momand, \& Finlay, 1991). Furthermore, mutant p53 function can be specific to cancer subtype (e.g., G>T transversions in lung cancer that do not correspond to the classic TP53 hotspot mutations) (Olive et al., 2004; Petitjean, Achatz, Borresen-Dale, Hainaut, \& Olivier, 2007). Recent studies comparing TP53 mutation status with outcome in rhabdomyosarcoma patients show that TP53 mutation status is correlated with increased risk and poor prognosis (Casey et al., 2020); however, the role for specific TP53 mutations on sarcoma progression remains to be defined.

TP53 mutations are present in $>40 \%$ of adult carcinomas and thought to play a major role in tumorigenesis (Grobner et al., 2018). In contrast, with some exceptions, mutations in TP53 are found in less than $6 \%$ of pediatric cancers (X. Chen et al., 2014; Chen et al., 2013; Grobner et al., 2018; Seki et al., 2015; Shern et al., 2014; Tirode et al., 2014). A major exception is Li-Fraumeni Syndrome, where germline TP53 mutations predispose to a unique tumor spectrum that includes soft tissue sarcomas, such as rhabdomyosarcoma, and bone tumors (Guha \& Malkin, 2017; Malkin, 2011). It is important to note that the TP53 pathway is often suppressed in sarcomas. For example, in human embryonal rhabdomyosarcoma (ERMS), a common pediatric cancer of muscle, the TP53 locus is mutated or deleted in $16 \%$ of tumors while transcriptional activity is altered in $>30 \%$ of tumors, either through direct locus disruption or MDM2 amplification (Chen et al., 2013; Seki et al., 2015; Shern et al., 2014; Taylor et al., 2000). TP53 mutations can also be acquired in ERMS at relapse, suggesting a role in tumor progression and/or resistance to therapy (Chen et al., 2013).

Mouse models have led the way in understanding Tp53 function in vivo. Several murine genetic models were developed to assess the effects of both loss- and gain-of-function Trp53 mutations (Attardi \& Donehower, 2005; Garcia \& Attardi, 2014) with mutant and null alleles both spontaneously developing cancer in multiple tissues (Lozano, 2010). Of note, the tumor spectrum in mice can vary depending on the mutant allele and genetic 
bioRxiv preprint doi: https://doi.org/10.1101/2021.04.21.440757; this version posted April 22, 2021. The copyright holder for this preprint (which was not certified by peer review) is the author/funder, who has granted bioRxiv a license to display the preprint in perpetuity. It is made available under aCC-BY 4.0 International license.

background; however, most in vivo studies have focused on a subset of hotspot mutations that are compared to the null or heterozygous wild type background and that are seen only in a subset of sarcoma patients (Attardi \& Donehower, 2005; Garcia \& Attardi, 2014; Guha \& Malkin, 2017)). The vast majority of mutations observed in patients have not been interrogated in animal models, but rather function is inferred from these commonly studied hotspot mutants. TP53 can have myriad effects on cancer biology and differences due to tumor type, mutation specific effects, or genetic background present significant challenges, with significant impact on therapeutic approaches in the clinic.

To define tp53 biology in vivo using zebrafish, we recently generated a complete loss-of-function tp53 deletion allele in syngeneic CG1-strain zebrafish using TALEN endonucleases (Ignatius et al., 2018). tp53 ${ }^{\text {del/del }}$ $\left(t p 53^{-/-}\right)$zebrafish spontaneously developed a spectrum of tumors that includes malignant peripheral nervesheath tumors (MPNSTs), angiosarcomas, germ cell tumors, and an aggressive natural killer cell-like leukemia (Ignatius et al., 2018). The role for tp53 in self-renewal and metastasis of $k R A S^{G 12 D}$-induced ERMS tumors was assessed using cell transplantation assays and revealed that $t p 53$ loss does not change the overall frequency of ERMS self-renewing cancer stem cells compared to tumors expressing wild-type tp53 (Ignatius et al., 2018). In contrast, $t p 53^{-/-}$ERMS were more invasive and metastatic compared to tp53 wild-type tumors, providing new insights into how tp53 suppresses ERMS progression in vivo. By taking advantage of the fact that in zebrafish, similar to humans, tp53 loss-of-function is not required for tumor initiation, we employ $t p 53^{-/-}$zebrafish in the present study to further assess the role for tp53 on $k R A S^{G 12 D}$-driven ERMS. We find that wild-type tp53 affects ERMS proliferation with a smaller effect on apoptosis. Next, expressing wild-type human TP53, we find that TP53 is functional in zebrafish and potently suppresses ERMS initiation in vivo. We also define the pathogenicity of two TP53 mutations, one found in a patient with ERMS and the other a variant of unknown significance found in a teenager with an aggressive osteosarcoma at our clinic. We find that these two mutations have very different effects on tumor initiation, location, proliferation, and apoptosis in our zebrafish model. Taken together, these analyses highlight the zebrafish ERMS model as a powerful and high-throughput system that can be used to characterize the spectrum of common and rare TP53 mutations in sarcoma patients in the clinic. 
bioRxiv preprint doi: https://doi.org/10.1101/2021.04.21.440757; this version posted April 22, 2021. The copyright holder for this preprint (which was not certified by peer review) is the author/funder, who has granted bioRxiv a license to display the preprint in perpetuity. It is made available under aCC-BY 4.0 International license.

\section{Results}

\section{tp53 is a potent suppressor of ERMS initiation, growth and invasion.}

Whole genome/exome/transcriptome sequencing analysis revealed that a majority of primary ERMS tumors are wild-type for TP53. However, TP53 loss, mutation, or MDM2 amplification accounts for pathway disruption in approximately 30\% of ERMS (Chen et al., 2013; Seki et al., 2015; Shern et al., 2014). Furthermore, TP53 mutation is associated with poor prognosis (Casey et al., 2020). In the zebrafish ERMS model, expressing the human $k R A S^{G 12 D}$ oncogene in muscle progenitor cells is sufficient to generate ERMS with morphological and molecular characteristics that recapitulate the human disease (Langenau et al., 2007). Although robust, in a tp53 wild-type genetic background, the upper limit of tumor formation observed is $40 \%$ by 50 days post injection/fertilization (Langenau et al., 2007). To test whether tp53 suppresses ERMS initiation in vivo, we generated tumors in $t p 53$ wild-type $\left(t p 53^{+/+}\right)$and $t p 53^{-/-}$mutant zebrafish and compared aspects of tumorigenesis, including ERMS onset and growth. Co-injection of $k R A S^{G 12 D}$ and DsRed under the rag2 promoter resulted in approximately $34 \%$ of $t p 53^{+/+}$animals ( $n=49 / 143$ animals) with tumors by 60 days post injection. In stark contrast, $>97 \%$ of $t p 53^{-/}$animals displayed tumors ( $n=139 / 142$ animals) by 60 days. $k R A S^{G 12 D_{\text {-induced }} \text { tp53 }}{ }^{-/}$ERMS displayed a very rapid onset, with the majority of tumors arising within the first 20 days of life (Figure 1A; $p<0.0001)$. We assessed tumor size and number of tumors initiated per zebrafish and found that $t p 53^{-/-}$mutant ERMS displayed a significant increase in size (Figure $1 \mathrm{~B}, \mathrm{D} ; p<0.0001$ ) and in the number of tumors per animal (Figure 1B, C; $p=0.016$ ), compared to $t p 53^{+/+}$animals. Assessment of histology showed no major differences between $t p 53^{+/+}$and $t p 53^{-/}$ERMS, and tumors formed in the head, trunk, or tail similarly in both backgrounds (Figure 1E, F, Figure S1B). We assessed relative expression of $k R A S^{G 12 D}$ and its downstream effector dusp4 in tumors from $t p 53^{-/}$and $t p 53^{+/+}$zebrafish and confirmed similar expression levels of $k R A S^{G 12 D}$ and dusp4 using quantitative qPCR (Figure S1A; $n=3$ tumors each, $p=0.8966$ Unpaired t test with Welch's correction). Taken together, our analysis suggests that tp53 is a major suppressor of tumor initiation in RAS-driven zebrafish ERMS.

We next assessed the role for tp53 loss-of-function on ERMS tumor growth by following tumor-burdened animals over time. Similarly aged wild-type and $t p 53^{--}$tumors were imaged once a week over the course of 3 weeks. While wild-type ERMS grew large tumors that remained localized, tumors in $t p 53^{-/}$ERMS grew larger in size and spread very rapidly past neighboring somites (Figure S1C-E; $p=0.054$ in week $1 ; p<0.0001$ in week 2 and 3; Student's t test). We also observed metastases at locations away from the primary tumors in $t p 53^{-1-}$ 
zebrafish (Figure S1C, $t p 53^{-/-}$fish 3). The invasive metastatic behavior of primary tp53-- tumors is consistent with our earlier analysis that found transplanted secondary and tertiary $t p 53^{-/}$tumors are highly metastatic using an in vivo metastasis transplantation assay (Ignatius et al., 2018).

\section{tp53 suppresses proliferation and to a lesser extent apoptosis in ERMS tumors}

Given that $t p 53^{-/}$tumors are larger than equivalent stage wild-type tumors, we performed EdU and phospho-histone $\mathrm{H} 3$ staining to assess proliferation and Annexin $\mathrm{V}$ staining to assess apoptosis in primary ERMS. Treatment of wild-type and $t p 53^{-/-}$tumors with a 6 -hour pulse of EdU revealed that $t p 53^{-/-}$tumors are significantly more proliferative (Figure 2A; $p=0.0002$ Student's T-test). Similarly, tp53 ${ }^{-/}$ERMS displayed significantly more phospho-histone H3-expressing cells when compared to tp53 wild-type ERMS (Figure 2B; $p$ $<0.0001$ Student's T-test). Analysis of Annexin $\mathrm{V}$ staining for apoptotic tumor cells showed no significant difference in the rate of late apoptosis (Q2) (Figure 2C-E; $p=0.592$ Student's $t$ test), but rather a small yet significant decrease in early apoptosis (Q4) in tp53\% mutant ERMS compared to wild-type (Figure 2C-E; $p=$ 0.0073 Student's T test). Taken together, our data suggests $t p 53$ is a potent suppressor of tumor cell proliferation, with a moderate effect on apoptosis during ERMS tumorigenesis.

\section{Reintroducing human TP53 in tp53--- zebrafish blocks tumor initiation, growth, proliferation and increases}

\section{apoptosis}

We next assessed the consequence of introducing wild-type human TP53 (TP53 $\left.{ }^{W T}\right)$ in ERMS tumors in tp53\% ${ }^{-/}$animals. Co-expression of $k R A S^{G 12 D}$ along with $T P 53^{W T}$ significantly suppressed tumor initiation (Figure $3 A ; p<0.0001$, Student's t test). ERMS in TP53 ${ }^{W T}$-expressing animals grow more slowly and were unable to spread and/or metastasize (Figure 3B). The few tumors that did arise in TP53 ${ }^{W T}$-expressing animals were smaller (Figure 3C; $p<0.0001$ Student's t test); however, there was no difference in the number or distribution of ERMS initiated per zebrafish between the two groups (Figure 3D, $\mathrm{E} ; p=0.065$ for $\mathrm{D}$, Student's t test). Analysis of EdU staining of ERMS tumors determined that co-expressing TP53 ${ }^{W T}$ significantly inhibits proliferation (Figure $3 F ; p=0.0007$ Student's t test). Also, we observed an overall increase in the number of apoptotic cells in TP53 ${ }^{W T}$ expressing tumors as seen by Annexin V staining (Figure 3G; $p<0.0001$ Student's t test). We also assessed the effects of $T P 53^{W T}$ on tumor initiation in the $t p 53^{+/+}$background and found no difference in the rate of tumor 
initiation for both groups (Figure S3A). Similarly, expression of wild-type zebrafish tp53 by co-expression with $k R A S^{G 12 D}$ in $t p 53^{-/-}$zebrafish significantly suppressed tumor initiation (Figure S3B, C; $p<0.0001$ Student's $t$ test).

Furthermore, we found that this effect is dose-dependent, with co-expression of lower levels of tp53 resulting in reduced suppression of tumor initiation in $t p 53^{-/-}$zebrafish (Figure S3B; $p<0.0001$ Student's t test). Importantly, expression of human $T P 53^{W T}$ or wild-type zebrafish tp53 selectively in ERMS using the rag2 promoter had no effect on the overall viability of zebrafish embryos or larvae.

\section{Assigning pathogenicity to $T P 53^{P 153 \Delta}$ and $T P 53^{C 176 F}$, two undefined mutations in human sarcomas}

The effects of specific TP53 mutations on ERMS tumorigenesis are not defined. Analysis of TP53 mutations in RMS patients found that a majority of mutations lie outside the well-studied hotspot locations and are mostly uncharacterized (Figure S4A). To determine if ERMS expressing specific human TP53 point mutations differ from TP53 deletion, we decided to study two uncharacterized mutations in vitro in SaOS2 osteosarcoma cells and in vivo by assessing mutant activity in ERMS generated in $t p 53^{-/-}$zebrafish. SaOS2 cells have the TP53 gene deleted and provide a commonly used assay system to study effects of wild-type, hypomorphic, and gain-of-function effects in comparison to the TP53 ${ }^{-/}$background (Marcellus, Teodoro, Charbonneau, Shore, \& Branton, 1996). The first mutation we selected is a TP53 ${ }^{C 176 F}$ allele that is expressed by at least two patients with ERMS (Chen et al., 2013; Seki et al., 2015). In one of these patients, the second TP53 allele was deleted in the tumor and the mutation is present in both the primary and relapsed tumor (Chen et al., 2013). The other mutation we selected to model is a rare $T P 53^{P 153 \Delta}$ (deletion of Proline $153, P 153 \Delta$ ) allele present in a patient in our clinic with an aggressive osteosarcoma. The patient developed an aggressive refractory osteosarcoma as a teenager, while her mother developed osteosarcoma in her early twenties; both succumbed to their disease. Based on the patient's family history, tumor type, and TP53 mutation, the diagnosis of LiFraumeni syndrome was rendered. However, since the mutation was rare, pathogenicity could not be assigned to this particular allele. Analysis of amino acid sequence conservation showed that residue $\mathrm{C} 176$ is conserved across humans, mouse, and zebrafish. On the other hand, P153 is present only in humans; however, it is located in a region that is highly conserved across all three species and the P153 is also conserved across other closely related mammalian species (Figure $4 A$, S4B). We confirmed the TP53 ${ }^{P 1534}$ mutation by sequencing the DNA 
from the first passage patient-derived xenograft (PDX) generated from the patient at autopsy. Tumor cells obtained from the patient also harbored a missense mutation at c.476C>T (p.A159V) (Figure 4B).

We next assessed if the $\mathrm{p} 53^{\mathrm{C} 176 \mathrm{~F}}$ and $\mathrm{p} 53^{\mathrm{P} 153 \Delta}$ proteins were expressed in the ERMS PDX SJRHB00011 that harbors the $T P 53^{C 176 F}$ mutation and in the primary osteosarcoma that harbors the $T P 53^{P 1534}$ mutation using immunohistochemistry on tumor sections (Chen et al., 2013). Both the SJRHB00011 PDX tumor and the primary osteosarcoma tumor expressed p53 protein, as evidenced by strong positive nuclear staining in the majority of tumor cells (Figure 4C, D). Further H\&E staining confirmed the rhabdomyosarcoma (heterogeneous population of ovoid to slightly spindled cells; Figure 4E) and osteosarcoma diagnosis (pleomorphic neoplastic tumor cells with irregular disorganized trabeculae of unmineralized malignant osteoid; Figure 4F).

To determine the effects of these mutations on tumorigenesis, we expressed either wild-type p53 (p53 ${ }^{\mathrm{WT}}$ ) or mutant $\mathrm{p} 53^{\mathrm{C} 176 \mathrm{~F}}$ or $\mathrm{p} 53^{\mathrm{P} 153 \Delta}$ proteins in TP53-null SaOS2 osteosarcoma cells using a Doxycycline (Dox)inducible vector (Figure 4G). Surprisingly, we find that only Dox-induced expression of wild-type p53 protein resulted in a reduction of cell growth (Figure $4 \mathrm{H}, \mathrm{I}, p<0.0001$ ). We next assessed the ability of mutant and wildtype p53 proteins to activate transcription using a luciferase-based reporter containing 13 copies of the p53-DNA binding consensus sequence (el-Deiry et al., 1993), and again found that only wild-type p53 could drive significant transcriptional activity (Figure 4J, $p<0.0001$ ). Next, we assessed the ability of mutant and wild-type p53 to suppress colony formation in vitro. Consistent with earlier results, expression of wild-type TP53 reduced colony formation compared to empty vector controls; however, expression of TP53 ${ }^{P 1534}$ and TP53 ${ }^{C 176 F}$ did not result in changes in colony formation compared to uninduced or SaOS2 control cells (Figure 4K, L, $p<0.0001$, Dunnett's multiple comparisons test). Using a Caspase-3/7 Glo apoptosis assay, we found that cells expressing wild-type p53 (+Dox) efficiently induced apoptosis. In contrast, uninduced control (-Dox) or cells expressing mutant p53 protein did not induce apoptosis (Figure 4M, $p<0.0001$, two-way ANOVA with Sidak's multiple comparisons test). Finally, compared to uninduced controls or cells expressing mutant p53 proteins, cells expressing wild-type p53 robustly induced p21 expression (Figure 4N). Thus, our in vitro results indicate that both TP53 mutations (TP53 ${ }^{P 1534}$ and TP53 ${ }^{C 176 F}$ ) fail to retain wild-type function and do not show any gain-offunction activity in the SaOS2 TP53\%- background. 




\section{I- zebrafish}

We next assessed the two TP53 mutations in ERMS generated in tp53/- zebrafish. We co-expressed $T P 53^{C 176 F}$ or TP53 ${ }^{P 1534}$ along with $k R A S^{G 12 D}$ in $t p 53^{-/-}$embryos, as previously described. Expression of the mutant proteins in ERMS tumors was confirmed by Western blot analysis, using a human specific p53 antibody. For this assay, mutant p53 expression in Rh30 RMS cells was utilized as a positive control while zebrafish tp53- ERMS cells were used as a negative control (Figure 5A). Expression of TP53 ${ }^{C 176 F}$ with $k R A S^{G 12 D}$ in $t p 53^{-/}$embryos resulted in a significant reduction in the initiation of tumors compared to expressing $k R A S^{G 12 D}$ alone in $t p 53^{-/-}$ zebrafish (Figure $5 \mathrm{~B}, p=0.0005$ ), while expression of $T P 53^{P 153 \Delta}$ along with $k R A S^{G 12 D}$ in the $t p 53^{-/}$background resulted in similar rates of tumor initiation (Figure $5 B, p=0.774$ ). We also assessed the effects of $T P 53^{C 176 F}$ and $T P 53^{P 1534}$ on tumor initiation in the wild-type tp53/++ background and found no difference in the rate of tumor initiation for either of the mutant proteins (Figure $5 \mathrm{C}, p=0.972$ ).

Next, we assessed TP53 ${ }^{C 176 F}$ and TP53 ${ }^{P 1534}$-expressing tumors for tumor incidence and location. While the number of primary ERMS per fish in $t p 53^{-/}+T P 53^{P 153 \Delta}$ were similar to $t p 53^{-/}$or $t p 53^{-/}+T P 53^{C 176 F}$-expressing animals (Figure S5A, Versus tp53 ${ }^{--}, p=0.065\left(\right.$ TP53 $\left.^{C 176 F}\right), p=0.9299\left(\right.$ TP53 $\left.^{P 1534}\right)$, one-way ANOVA with Tukey's multiple comparisons test), rather unexpectedly, $t p 53^{-/}+T P 53^{P 1534}$-expressing zebrafish had greater than twice as many ERMS initiated in the head musculature (Figure 5D, E, $p=0.0096$, Two Proportions $Z$ test) indicating a gain-of-function effect with respect to site of tumor initiation.

Similarly, we assessed the effects of the TP53 mutations on proliferation and apoptosis. The $t p 53^{-/}$and


expressing ERMS (Figure S5B, C, $p=0.0062$ ), while only $T P 53^{C 176 F}$ tumors showed significantly higher rates of apoptosis, compared to the other two groups (Figure 5F, $p=0.0002$ ). Tumor histology remained unchanged across all three groups (Figure 5G). Given that the TP53 ${ }^{C 176 F}$ mutation retains the ability to induce apoptosis, we next tested whether this activity could be augmented to inhibit tumor growth in vivo. It has been shown previously that ZMC1, a synthetic metallochaperone that transports zinc into cells as an ionophore, can restore p53 activity 
by stabilizing mutant $\mathrm{p} 53$ proteins such as p53 ${ }^{\mathrm{C} 176 \mathrm{~F}}$ (Blanden et al., 2015). To test this, we generated ERMS in the syngeneic CG1 strain zebrafish that were either $t p 53^{-/}$or $t p 53^{-/}+T P 53^{C 176 F}$. Next, we expanded tumors from both groups in recipient wild-type CG1 animals, and treated tumors in recipient host animals for 2 weeks with either DMSO or ZMC1. Compared to DMSO-only control treatment, $t p 53^{-/}+T P 53^{C 176 F}$-expressing ERMS treated with ZMC1 showed a significant reduction in tumor growth over time (Figure S5D, G; $p=0.0032$ at week 3). We next assessed effects of ZMC1 on apoptosis via Annexin $V$ staining and found that $t p 53^{-/}+T P 53^{C 176 F}$ expressing tumors treated with ZMC1 displayed increased apoptosis after drug treatment (Figure S5F; $p=0.0008$ ). Finally, we assessed $\mathrm{p} 53^{\mathrm{C} 176 \mathrm{~F}}$ expression and found that $\mathrm{ZMC1}$ treatment increased protein levels, suggesting increased stability of $\mathrm{p} 53^{\mathrm{C} 176 \mathrm{~F}}$ protein (Figure S5E). In contrast, $t p 53^{-/-}$only ERMS treated with ZMC1 did not have any effect on the tumor growth (Figure S5H, K, $p=0.961$ ) or apoptosis (Figure S5I-J, $p=0.583$ ).

Altogether, we found that the TP53 ${ }^{P 1534}$ mutation functions as a gain-of function allele with respect to the site of tumor initiation, while TP53 ${ }^{\mathrm{C} 176 \mathrm{~F}}$ appears to retain some wild-type function, resulting in decreased ERMS initiation compared to tumor initiation in the $t p 53^{-/-}$background and the retention of the ability to trigger apoptosis in vivo. Additionally, the partial wild-type apoptotic activity of $\mathrm{p} 53^{\mathrm{C} 176 \mathrm{~F}}$ can be further enhanced by treatment with p53 reactivators, such as ZMC1.

\section{Expression of $T P 53^{Y 220 C}$ predisposes to head ERMS in zebrafish}

There is only one report of a patient with the $T P 53^{P 1534}$ mutation who had a predisposition to multiple cancers including breast cancer, soft tissue sarcoma and lung cancer (Michalarea et al., 2014). The location of the deleted proline suggests that the mutation causes a structural change in p53, therefore, we sought to understand the effect of this mutation on function by assessing protein structure and stability using in silico modeling. Homology models of $\mathrm{p} 53^{\mathrm{P} 153 \Delta}$ generated by SWISS-MODEL (Waterhouse et al., 2018) indicate that deletion of P153 causes a partial narrowing of a small pocket on the surface of p53 ${ }^{\mathrm{WT}}$ (Figure 6A). P153 is the C-terminal residue of a tri-proline surfaced exposed loop that retains flexibility and mobility. Conversely, another known $p 53$ mutation, the $\mathrm{p} 53^{\mathrm{Y} 220 \mathrm{C}}$ mutation, causes an expansion and deepening of this pocket by forming a cleft bounded by L145, V147, T150- P153, P222, and P223 (Figure 6A). We searched the TCGA data base for other TP53 mutants sequentially and structurally close to P153 and identified proline residues P151 and P152 are also mutated in cancers. Interestingly, we found mutations in P151 and P152 are present in a subset of tumors in the 
bioRxiv preprint doi: https://doi.org/10.1101/2021.04.21.440757; this version posted April 22, 2021. The copyright holder for this preprint (which was not certified by peer review) is the author/funder, who has granted bioRxiv a license to display the preprint in perpetuity. It is made available under aCC-BY 4.0 International license.

TCGA data base overlapping with the Y220C mutation (TCGA Research Network data; http://cancergenome.nih.gov). Previous molecular dynamics simulations of p53 ${ }^{\mathrm{Y} 220 \mathrm{X}}(\mathrm{X}=\mathrm{C}, \mathrm{H}, \mathrm{N}$ or $\mathrm{S})$ mutants found that the tri-proline loop (P151-153) is mobile and can precipitate a concerted collapse of the pocket, forming a frequently populated closed-state and contributing to the instability of p53 (Bauer et al., 2020). Since the binding of small molecules in the pocket increases the stability of $p 53^{\Upsilon 220 X}$ mutants, it is not inconceivable that mutations lining this pocket such as the tri-proline loop could be involved in fluctuations that decrease the structural stability of p53. Similarly, in our static models presented here, the loss of P153 causes this pocket to be slightly occluded and could contribute to further destabilization and effect p53 function. (Figure 6A). The TP53 ${ }^{\text {Y220C }}$ mutation is the ninth most frequent TP53 missense mutation and is the most common "conformational" TP53 mutation in cancer (Baud et al., 2018). Interestingly, the TP53 ${ }^{\text {Y220C }}$ allele is frequently associated with sarcomas and head and neck carcinomas and has been reported in patients with osteosarcoma and rhabdomyosarcoma (Castresana et al., 1995; Overholtzer et al., 2003). We therefore hypothesized that loss of P153 via an in-frame deletion might result in similar structural defects as the Y220C mutant by contributing to the overall structural instability of p53 (Wang \& Fersht, 2017). Based on this hypothesis, we predicted that ERMS tumors expressing TP53 ${ }^{Y 220 C}$ may phenocopy TP53 ${ }^{P 1534}$ with increased ERMS in the head region. To test this hypothesis, we generated ERMS that expressed TP53 ${ }^{\mathrm{Y} 220 \mathrm{C}}$ with $k R A S^{G 12 D}$ and GFP in $t p 53^{-/-}$embryos. Western blot analyses confirmed that mutant $\mathrm{p} 53^{\mathrm{Y} 220 \mathrm{C}}$ protein was expressed (Figure 6B). Kaplan-Meier analyses indicated that while TP53 ${ }^{\mathrm{Y} 220 C}$ expression inhibited ERMS initiation (Figure 6C, $p<0.0001$ ), decreased the number of primary ERMS per fish (Figure S6A, $p<0.0001$ ), TP53 ${ }^{Y 220 C}$ expression also led to a significant increase in


animals expressing $T^{P} 53^{P 1534}$ (Figure 6D, F, H and Figure S6B; 31.1\% of ERMS; n=150). We confirmed ERMS pathology by performing H\&E staining on tumor sections (Figure 6E, G). As seen with TP53 ${ }^{P 1534}$, TP $^{2} 3^{\text {Y220C }}$ expression led to a decrease in tumor cell proliferation (Figure $6 \mathrm{~J}, p<0.0001$ ); however, TP53 ${ }^{\mathrm{Y} 220 \mathrm{C}}$ expression also significantly increased apoptosis rates (Figure $6 \mathrm{I}, p=0.001$ ), unlike that seen in TP53 ${ }^{P 1534}$-expressing ERMS. We next assessed if TP53 ${ }^{\mathrm{Y} 220 \mathrm{C}}$ expression in SaSO2 cells displayed oncogenic activity. Similar to p53 ${ }^{\mathrm{C} 176 \mathrm{~F}}$ and $\mathrm{p} 53^{\mathrm{P} 1534}, \mathrm{p} 53^{\mathrm{Y} 220 \mathrm{C}}$ showed no discernible transcriptional activity compared to wild-type $\mathrm{p} 53$, as measured by the luciferase reporter assay and induction of p21 protein expression (Figure $6 \mathrm{~K}, \mathrm{~L}, p=0.884$ ). p53 ${ }^{\mathrm{Y} 220 \mathrm{C}}$ also had no effect on SaOS2 growth or colony formation compared to wildtype p53 (Figure S6C-E, $p=0.283$ (D, Ordinary 
bioRxiv preprint doi: https://doi.org/10.1101/2021.04.21.440757; this version posted April 22, 2021. The copyright holder for this preprint (which

was not certified by peer review) is the author/funder, who has granted bioRxiv a license to display the preprint in perpetuity. It is made available under aCC-BY 4.0 International license.

one-way ANOVA with Tukey's multiple comparisons test - Scr + Dox vs TP53 ${ }^{\text {Y220C }}+$ Dox $), p=0.1713(\mathrm{E}$, Unpaired $t$ test)). Finally, the $\mathrm{p} 53^{\mathrm{Y} 220 \mathrm{C}}$ protein was unable to induce apoptosis when expressed using a Doxinducible promoter and assessed by a caspase 3/7 apoptosis assay (Figure S6F, $p=0.5608$, Welsh's t test).

Altogether, our data reveal that both the $T P 53^{P 1534}$ and $T P 53^{Y 220 C}$ mutations predispose to head ERMS tumors in zebrafish but differ in their effects on tumor initiation and apoptosis. However, similar to TP53 ${ }^{\mathrm{C} 176 \mathrm{~F}}$ and TP53 ${ }^{P 1534}$ mutants in vitro in SaSO2 cells, TP53 ${ }^{Y 220 C}$ does not show any effects on colony formation, transcriptional activity, proliferation, or apoptosis.

\section{Discussion}

The TP53 tumor-suppressor gene is mutated in $>40 \%$ of human tumors, and patients with Li-Fraumeni syndrome with germ line mutations are predisposed to a spectrum of tumors that includes several potentially lethal childhood sarcomas, such as rhabdomyosarcoma and osteosarcoma (Grobner et al., 2018; Guha \& Malkin, 2017). Here, we addressed three poorly understood aspects of TP53 function in ERMS, a devastating pediatric malignancy of the muscle. First, we found that the tp53 pathway is a major suppressor of tumor initiation in RAS-driven ERMS. Second, we found that human TP53 can complement zebrafish tp53 function. Third, we assigned function to two mutations whose effect in ERMS was previously unknown and defined TP53 ${ }^{\mathrm{C} 176 \mathrm{~F}}$ and $T P 53^{P 1534}$ as a hypomorphic allele and pathogenic gain-of-function mutation, respectively. Lastly, we found that the structural mutations TP53 $3^{P 1534}$ and TP53 ${ }^{Y 220 C}$ predispose to head musculature ERMS.

Mutant RAS-driven ERMS tumors are associated with high-risk patients and are a challenge to treat in the clinic. RAS mutant ERMS models in mice are generated by introducing mutant RAS along with switching off Trp53 and/or p16 (Kashi, Hatley, \& Galindo, 2015). In contrast, zebrafish ERMS is more similar to the human disease since RAS activation is sufficient to drive tumor formation. However, a maximum of $40 \%$ of wild-type $k R A S^{G 12 D}$-expressing zebrafish initiate tumors by 50 days of life (Langenau et al., 2007). In both the zebrafish and human tumors with wild-type tp53, a subset of tumors have MDM2 amplification and/or overexpression (Chen et al., 2013; Langenau et al., 2007; Seki et al., 2015; Shern et al., 2014). Additionally, other genes such as TWIST1 have also been shown to promote tumor initiation in ERMS and sarcomas through suppression of p53 expression (Piccinin et al., 2012). Of note, in the zebrafish ERMS model, it was previously shown that incidence was increased to approximately $70 \%$ of animals in the $t p 53^{M 214 K / M 214 K}$ mutant background (Berghmans 
et al., 2005; Langenau et al., 2007), suggesting that tp53 plays an important role in suppressing ERMS initiation; however other pathways may also function to initiate RAS-driven ERMS in the remaining $30 \%$ of animals that remain tumor free. However, it is important to note that the recently generated $t p 53^{--}$complete loss-of-function

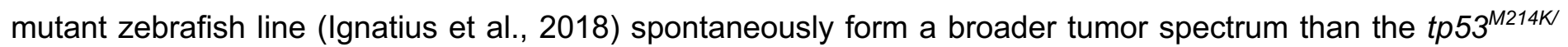
${ }^{M 214 K}$ allele, which includes MPNSTs, angiosarcomas, NK-cell leukemias, and germ cell tumors (Berghmans et al., 2005; Ignatius et al., 2018). Our study tests the role for complete loss of tp53 in ERMS initiation by generating $k R A S^{G 12 D}$-induced ERMS in the $t p 53^{-/}$background. We found that in the $t p 53^{--}$complete loss-of-function background $>97 \%$ of animals form tumors, indicating that tp53 pathway suppression is required for ERMS full tumor penetrance. Moreover, when compared to control wild-type animals, $t p 53^{-/}$animals initiate significantly more tumors per animal, display increased tumor cell proliferation, and exhibit a relatively less pronounced effect on tumor cell apoptosis. The effects on apoptosis can be enhanced through expression of either wild-type human TP53 or zebrafish tp53 under the control of the rag2 promoter, specifically in ERMS tumor cells. Our study also demonstrates that in primary tumors, tp53 is a potent suppressor of tumor cell growth, invasion, and metastasis, confirming earlier studies that used transplanted tumor cells into unlabeled syngeneic hosts (Ignatius et al., 2018). Our previous study also showed that loss of tp53 had no effect on tumor cell self-renewal (Ignatius et al., 2018). Thus, while TP53 is shown to suppress tumor progression by multiple mechanisms depending on tumor type, our results suggest that loss of TP53 in human ERMS may increase aggressiveness through enhanced proliferation, invasion, and metastasis.

A second important finding is that human TP53 can complement wild-type tp53 function in zebrafish ERMS, which allows for the study of different human alleles directly in vivo. Moreover, studying the effects of different levels of TP53 specifically in ERMS tumors does not drastically alter tumor phenotypes observed. The biggest difference observed was a slight increase in total Annexin-positive apoptotic cells; however, it is important to note that co-expression in vivo of mutant and wildtype p53 results is protein expression at comparable or at lower levels than present in human tumor cells that endogenously express mutant p53 protein. For example, our assays displayed lower p53 expression than that observed in Rh30 RMS cells, which express mutant p53 ${ }^{\text {R273C }}$ (Gibson, Harwood, Tillman, \& Houghton, 1998). Secondly, the co-expression approach we use has been applied to study multiple aspects of tumorigenesis in zebrafish including in ERMS, T-cell acute lymphoblastic leukemia (T-ALL), melanoma, liver cancer, and neuroblastoma (Blackburn et al., 2014; Langenau 
et al., 2007; Lobbardi et al., 2017; White, Rose, \& Zon, 2013). In zebrafish ERMS, co-expression approaches are used to study the effects multiple pathways have on tumorigenesis, including Notch signaling, canonical and non-canonical Wnt signaling, Myf5 and MyoD on tumorigenesis; moreover many of the effects seen were validated using human cell culture or in vivo in murine xenograft assays (E. Y. Chen et al., 2014; Hayes et al., 2018; Ignatius et al., 2017; Tenente et al., 2017).

Having defined that wild-type human TP53 indeed functions similarly to endogenous zebrafish tp53, we were able to assess three mutant forms of TP53 observed in sarcomas and show they have very different effects on tumorigenesis. The TP53 ${ }^{C 176 F}$ mutation was identified in a patient with ERMS, with loss of the second TP53 wild-type allele (Chen et al., 2013). A second TP53 ${ }^{P 1534}$ mutation was found to be germline in a patient with osteosarcoma. Finally, the TP53 ${ }^{\mathrm{Y} 220 \mathrm{C}}$ mutation is commonly found in sarcomas, including RMS and osteosarcoma (Castresana et al., 1995; Overholtzer et al., 2003). Using our in vivo assays, we were able to identify that the TP53 ${ }^{C 176 F}$ allele functions as a hypomorph with respect to ERMS initiation that retains the ability to induce apoptosis. The trunk is a common site of tumor initiation for ERMS in zebrafish, and there was a slight predisposition for the TP53 ${ }^{\mathrm{C} 176 F}$ allele to initiate tumors in the trunk. These findings are consistent with studies showing that the TP53 ${ }^{\mathrm{C} 176 \mathrm{~F}}$ allele does retain some aspects of wild-type p53 function, can form tetramers with wild-type p53, and can differentially induce TP53 target genes like NOXA, P53R2, GADD45, BAX, and WAF1 (Hoffman-Luca et al., 2015; Kato et al., 2003). Surprisingly, the TP53 ${ }^{\mathrm{C} 176 \mathrm{~F}}$ allele had no effect on colony formation when expressed in SaOS2 osteosarcoma cells, suggesting that this function was not maintained in this commonly used assay system. Our results are consistent with other reports showing that certain mutations that modulate stability of p53 often show a range of effects in vitro assays and altering the temperature in which the cells are grown can be used to study their function (Di Como \& Prives, 1998; Pfister \& Prives, 2017). Significantly, compounds like ZMC1 enhance p53-induced tumor cell apoptosis. ZMC1 is thought to stabilize mutant p53 protein through increasing $\mathrm{Zn}^{2+}$ ions in cells and decrease tumor growth (Blanden et al., 2020; Blanden et al., 2015; Yu, Vazquez, Levine, \& Carpizo, 2012). We found that ZMC1 effectively stabilizes mutant p53 ${ }^{\mathrm{C} 176 \mathrm{~F}}$ and selectively increases ERMS apoptosis in $t p 53^{-/-}+T P 53^{C 176 F}$ but not $t p 53^{-/-}$tumors, revealing an effective in vivo drug efficacy platform to identify therapeutic strategies for p53 mutant ERMS in the future. Together, our data shows that in the context of ERMS, the TP53 ${ }^{C 176 F}$ allele is likely hypomorphic and stabilizing the resulting mutant protein can be used to increase apoptosis in the context of treatments. 
bioRxiv preprint doi: https://doi.org/10.1101/2021.04.21.440757; this version posted April 22, 2021. The copyright holder for this preprint (which

was not certified by peer review) is the author/funder, who has granted bioRxiv a license to display the preprint in perpetuity. It is made available under aCC-BY 4.0 International license.

In contrast to $T P 53^{C 176 F}, T P 53^{P 153 \Delta}$ is rare with one known patient reported in the literature (Michalarea et al., 2014). The patient was diagnosed with multiple tumors over several decades including bilateral breast cancer, malignant fibrous histocytoma, and an EGFR mutant lung adenocarcinoma. Several members of the patient's family including her mother, maternal aunts, and maternal grandmother all died due to early onset cancers, meeting the criteria of a Li-Fraumeni diagnosis (Michalarea et al., 2014). The specific Proline 153 residue in human $\mathrm{p53}$, while in a region that is highly conserved across species, is not conserved in mice or zebrafish, presenting a challenge for modeling in vivo. Nevertheless, the Proline 153 residue is conserved between human and closely related mammalian species. Due to its rarity in the literature and the lack of animal models, genetic testing done through Invitae, a medical genetic testing provider, could not assign pathogenicity to TP53 ${ }^{P 1534}$; however, the genetics strongly suggest that this is a Li-Fraumeni mutation based on both the patient and her mother being predisposed to osteosarcoma at young ages. Moreover, the experience in the clinic was that the osteosarcoma in the patient was extremely aggressive and refractory to multiple anti-cancer agents. Notably, our in vivo studies found that $T P 53^{P 1534}$ predisposes to head ERMS and that tumors are relatively resistant to apoptosis. Presently, no other gene or pathway has been identified in zebrafish that predisposes to head tumors, and head ERMS tumors are infrequent compared to tumors in the trunk and tail. Moreover, the TP53 ${ }^{\text {Y220C }}$ mutant in zebrafish also predisposed to head ERMS, revealing two TP53 mutant proteins that have shared gain-of-function effects in ERMS, possibly suggesting that they may gain shared activity that predispose to head ERMS tumors.

Head and neck rhabdomyosarcomas form a significant subset of ERMS tumors, and currently the basis for predisposition to head and neck RMS tumors is not understood. In mice, expressing activated Smoothened protein in cells expressing ap2 results primarily in head and neck ERMS (Hatley et al., 2012). Smoothened is a key component of the Hedgehog signaling pathway that is commonly activated in ERMS (Drummond et al., 2018; Satheesha et al., 2016). However, cell of origin likely plays a major role, given that in an independent mouse model, activated Smoothened under the control of a more ubiquitously expressed promoter leads to ERMS tumors in other skeletal muscle populations (Mao et al., 2006). Our data suggests that differential features of TP53 alleles like TP53 ${ }^{P 1534}$ and TP53 ${ }^{Y 220 C}$ may also predispose patients to head ERMS, providing additional mechanistic insights into anatomical differences in sarcoma initiation. Further, human TP53 mutations and loss 
of tp53 in our zebrafish models clearly show that loss or mutant TP53 is associated with enhanced tumorigenic properties, suggesting a reason some head and neck RMS tumors may be typically more aggressive in nature.

In summary, our study reveals the zebrafish ERMS model to be an effective tool to define multiple aspects of wild-type TP53 tumor suppressor function and to delineate both partial loss-of-function and gain-of-function mutational effects in vivo. This is an especially useful tool for sarcomas where a majority of TP53 mutations remain uncharacterized. Different TP53 alleles identified in patient tumors have very different effects on tumorigenesis in vivo and can potentially respond differently to therapeutic compounds. Thus, the type of precision modeling demonstrated here promises to help further define patient-specific TP53 biology and improve clinical strategies in the future.

\section{Materials and Methods:}

\section{Animals}

Animal studies were approved by the UT Health San Antonio Institutional Animal Care and Use Committee (IACUC) under protocol \#20150015AR (mice) and 20170101AR (zebrafish). Zebrafish strains used in this work

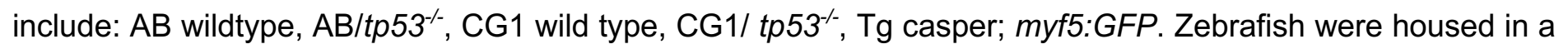
facility on a continuous flow system (Aquarius) with temperature-regulated water $\left(\sim 28.5^{\circ} \mathrm{C}\right)$ and a 14 -hour light10-hour dark cycle. Adult fish were fed twice daily with brine shrimp, supplemented with solid food (Gemma). Larval fish were kept off the continuous flow system until 15 days post-fertilization and supplemented with a paramecium/algae culture before transferred online.

\section{Generation of zebrafish rhabdomyosarcoma tumors}

rag2-kRASG12D and rag2-DsRed plasmids were linearized with Xhol, followed by phenol-chloroform extraction and ethanol precipitation. The purified DNA was resuspended in nuclease-free water (AM9916, ThermoFisher) and injected into embryos at the one-cell stage of development (40 ng/ $\mu$ l of rag2-kRASG12D and $20 \mathrm{ng} / \mu \mathrm{l}$ of rag2- DsRed). For expression of zebrafish tp53 or human TP53 in ERMS tumors in zebrafish, Xhol linearized rag2-kRASG12D and rag2- DsRed plasmids were injected along with Xmn1 linearized rag2-TP53 (human) or rag2-tp53 (zebrafish) constructs. For expression of mutant human TP53 experiments, tumors were 
generated by injecting Xhol linearized rag2-kRASG12D and rag2- DsRed or rag2-GFP along with Xmn1 linearized rag2-TP53 ${ }^{C 176 F}$, or TP53 ${ }^{P 1534}$, or TP53 ${ }^{\mathrm{Y} 220 C}$ into the one cell stage of zebrafish embryos $<1$ hour postfertilization (Ignatius et al., 2012; Langenau et al., 2007). Animals were allocated into experimental groups based on which injection cocktail they received during microinjection. Animals were monitored for tumor onset beginning at 10 days post-fertilization by scoring for DsRed or GFP fluorescence under an Olympus MVX10 stereomicroscope with an X-Cite series 120Q fluorescence illuminator. Scoring for tumor initiation was conducted for 60 days. The tumor onset was visualized by Kaplan-Meier plot, and the significance was analyzed by Logrank (Mantel-Cox) test for each two groups at a time. Sample size was determined taking into account the observed tumor initiation rates from previous studies using the zebrafish ERMS model (Langenau et al., 2008; Tenente et al., 2017).

\section{Tumor size (ratio) measurements}

Tumor size was measured using FIJI image analysis software (https://fiji.sc/) by comparing area occupied by the tumor region to the total body area of the fish. Specifically, all tumor-burdened fish were imaged in similar lateral position under both bright-field (white) and fluorescent light. The final representative images were generated by superimposing bright-field and fluorescence images using Adobe Photoshop. Significance was assessed by Student's t test.

\section{EdU staining}

5-ethynyl-2'-deoxyuridine (EdU, Molecular Probes, Life Technologies) was dissolved in DMSO to make a 10mM stock solution. This stock solution was further diluted 50 times using PBS to $200 \mu \mathrm{M}$, and $0.15 \mu \mathrm{l}$ and $0.3 \mu \mathrm{l}$ was injected into juvenile and older zebrafish, respectively. After 6 hours EdU treatment, tumor fish were euthanized with an overdose of MS-222 (Tricaine) and fixed in 4\% paraformaldehyde (PFA) at $4^{\circ} \mathrm{C}$ overnight. Then, the fixed samples were soaked using $25 \%$ sucrose (in PBS) at $4^{\circ} \mathrm{C}$ overnight. Finally, the samples were embedded in OCT medium and the medium was allowed to solidify on dry ice. Tissue was sectioned using a Leica CM1510 S Cryostat and tissue sections were placed on plus gold microscope slide (Fisherbrand). The slides were postfixed in 4\% PFA for 15 mins and permeabilized in 0.5\% Trition x-100 in BPS for 20 mins. Then, freshly made 
bioRxiv preprint doi: https://doi.org/10.1101/2021.04.21.440757; this version posted April 22, 2021. The copyright holder for this preprint (which

was not certified by peer review) is the author/funder, who has granted bioRxiv a license to display the preprint in perpetuity. It is made available under aCC-BY 4.0 International license.

Click-iT® Plus reaction cocktail was added to each slide and allowed to incubate for 30 mins. A small amount of Vectashield mounting medium with DAPI was added to the slide and covered with a coverslip. The EdU Click-iT Plus EdU Alexa Fluor 647 Imaging kit (Molecular Probes, Life Technologies) was used for EdU staining. Tissue sections were subsequently analyzed using an Olympus FV3000 confocal microscope. Significance was assessed by Student's $\mathrm{t}$ test. This assay was completed using at least 3 biological replicates (multiple primary tumors).

\section{qPCR Analysis}

Tumors were extracted from euthanized fish and homogenized inside a $1.5 \mathrm{ml}$ Eppendorf tube using a pestle connected to a Pellet Pestle ${ }^{\mathrm{TM}}$ Cordless Motor (DWK Life Sciences Kimble ${ }^{\mathrm{TM}}$ Kontes ${ }^{\mathrm{TM}}$ ). Tumor RNA was extracted using NEB's Monarch RNA mini prep kit. cDNA was synthesized from the extracted RNA using Invitrogen's First Strand Synthesis cDNA kit. Following cDNA synthesis, real-time qPCR was performed in 384well plates using Applied Biosystem's Sybr Green qPCR MasterMix (Comparative Cт $(\Delta \Delta \mathrm{CT})$ method). Results were compiled and analyzed using the QuantStudio 7 Flex system (Applied Biosciences). PCR primers are provided in Table 1. All assays were completed using technical replicates, with at least 3 tumors tested per experimental group.

\section{Phospho-histone H3 staining}

Fish were fixed in $4 \%$ PFA at $4^{\circ} \mathrm{C}$ overnight. The fixed fish were subsequently soaked in $25 \%$ sucrose overnight and then embedded in OCT medium before being sectioned at $10 \mu \mathrm{m}$ with a Leica CM1510 S cryostat. After being washed three times in PBST (0.1\% Triton X-100 and 0.1\% Tween 20 in PBS), the sections were incubated in blocking solution ( $2 \%$ horse serum, $10 \%$ FBS, $0.1 \%$ Triton X-100, $0.1 \%$ Tween $20,10 \%$ DMSO in PBS) for $60 \mathrm{~min}$. The sections were then incubated with rabbit anti-phospho-histone H3 (Ser10) primary antibody (1:500 dilution) at $4^{\circ} \mathrm{C}$ overnight. The following day, sections were washed three times in PBST and incubated with Alexa Fluor 647 conjugated anti-rabbit secondary antibody at room temperature for 2 hours. Vectashield mounting medium with DAPI was added to the slide and then a coverslip was placed over the sample. The slides were dried in the dark and sealed by nail polish. Sections were imaged using an Olympus FV3000 confocal 
microscope. Significance was assessed by Student's T test. This assay was completed using at least 3 biological replicates (multiple primary tumors).

\section{Annexin V-FITC/PI staining}

Fish were euthanized and tumor was isolated, following which the tumor was homogenized in $0.9 x$ PBS $+5 \%$ FBS manually using a razor blade and made into single suspensions using 45 micron filters. Tumor cells were washed with $0.9 x$ PBS $+5 \%$ FBS and resuspended in the binding buffer containing Annexin V-FITC and Propidium lodide for $15 \mathrm{~min}$ in the dark at room temperature. Then the cells were detected by flow cytometry (FCM, FACS Canto ${ }^{\text {TM }}$, BD, CA, USA). Significance was assessed by Student's T test. This assay was completed using at least 3 biological replicates (multiple primary tumors).

\section{Histology and immunohistochemistry}

Euthanized zebrafish were fixed in $4 \%$ PFA overnight at $4^{\circ} \mathrm{C}$. Embedding, sectioning, and immunohistochemical analysis of zebrafish sections were performed as previously described (E. Y. Chen et al., 2014; Ignatius et al., 2012). H\&E staining was performed at the Greehey CCRI histology core. Slides were imaged using a Motic EasyScan Pro slide scanner. Pathology review and staging were completed by board-certified pathologist (E.Y.C and A.R.G).

\section{Cloning TP53 wild-type and mutants constructs}

Wild-type TP53 from both human (Addgene plasmid \#69003) or zebrafish (3 days old embryos cDNA) were amplified by PCR and cloned into pENTR-D-TOPO vector, which was verified by DNA sequencing. rag2-TP53 (human) or rag2-tp53 (zebrafish) plasmids were generated by one-step Gateway reaction between a Gatewaycompatible plasmid with the zebrafish rag2 promoter flanked by attR sites and the respective pENTR-D-TOPO plasmid. TP53 ${ }^{C 176 F}$, TP53 ${ }^{P 1534}$, or TP53 ${ }^{\text {Y220C }}$ fragments were constructed by amplifying human TP53 as two separate fragments with the respective mutations, with the 3 ' end of the first fragment possessing $60 \mathrm{bp}$ of homology with the 5' end of the second fragment. These two fragments were purified from a $1 \%$ agarose gel using a Macherey-Nagel purification kit and spliced together using overlap extension PCR with Phusion ${ }^{\mathrm{TM}}$ high fidelity DNA polymerase (Szymczak-Workman, Vignali, \& Vignali, 2012). The entire spliced fragment was then blunt-ligated into a pENTR-D-TOPO vector. The TP53 insert was sequenced after which it was cloned into a 
bioRxiv preprint doi: https://doi.org/10.1101/2021.04.21.440757; this version posted April 22, 2021. The copyright holder for this preprint (which was not certified by peer review) is the author/funder, who has granted bioRxiv a license to display the preprint in perpetuity. It is made available under aCC-BY 4.0 International license.

Gateway-compatible plasmid with the zebrafish rag2 promoter flanked by attR sites using a one-step Gateway reaction using Gateway ${ }^{\mathrm{TM}}$ LR Clonase ${ }^{\mathrm{TM}}$ Enzyme mix. All other PCR amplification was carried out using Q5 high fidelity DNA polymerase.

\section{Western Blot Analyses}

Western blot analysis on fish tumors was performed by first extracting tumor from fish and homogenizing tumor cells suspended in SDS lysis buffer inside a $1.5 \mathrm{ml}$ Eppendorf tube using a pestle connected to a cordless motor. The total protein concentration for each lysate solution were normalized with a BCA assay kit (Thermo Fisher Scientific, Carlsbad, CA, USA). Then, $40 \mu \mathrm{g}$ of total protein was run on a $10 \%$ SDS/PAGE gel. The protein transferred membrane were blocked using 5\% fat free milk in TBST, followed by incubation in the appropriate antibody (anti-p53 antibody (1:1000 dilution in 5\% BSA), anti-GAPDH (control, 1:1000 in 5\% BSA), anti-p21 antibody (1:2000 dilution in 5\% BSA).

\section{In vitro cell growth and colony formation assays}

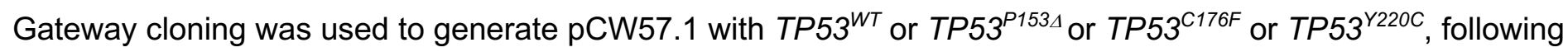
which the TP53 inserts were verified by DNA sequencing. These plasmids were transduced into a SaOS2 cell line via lentiviral infection using puromycin selection. The resultant puromycin-resistant stable line was treated with $2 \mu \mathrm{g} / \mathrm{ml}$ Dox for 2 days to induce TP53 expression. Western blot analysis was carried out to check TP53 expression in these cells. These cells were also seeded into 24 -well plates at $20 \%$ confluency and stored at $37^{\circ} \mathrm{C}$ in the Incucyte ZOOM (Essen Bioscience). Cell confluency (\%) was monitored every 4 hours over a period of 4 days. For colony formation assays, cells were seeded in 12 well plates (300 - 600 cells/well). After 24h, Dox was added to the wells at $2 \mu \mathrm{g} / \mathrm{ml}$ concentration. Incubation time for colony formation assays were around $\sim 2-3$ weeks. When colonies were sufficiently large, media was gently removed from each plate by aspiration, and colonies were fixed with $50 \%$ methanol for 30 minutes at room temperature. Colonies were then stained with $3 \%$ $(\mathrm{w} / \mathrm{v})$ crystal violet in $25 \%$ methanol for 15 minutes at room temperature, and excess crystal violet was washed with $\mathrm{dH} 2 \mathrm{O}$ with plates being allowed to dry. Colony formation was analyzed using ImageJ (Fiji). Significance was calculated by one-way ANOVA with Dunnett's multiple comparisons tests. All assays were performed using technical triplicates, and at least 3 biological replicates were completed. 


\section{Identifying TP53 mutation status in Osteosarcoma PDX sample}

DNA sample from osteosarcoma PDX was isolated using the Qiagen Puregene Core Kit A. PDX sample was first homogenized in lysis buffer, followed by heating at $65^{\circ} \mathrm{C}$ for 30 minutes. Thereafter, RNAse A was added to the sample and incubated for 30 minutes at $37^{\circ} \mathrm{C}$. Protein Precipitation buffer was used to precipitate protein, and the sample was vortexed and then centrifuged at 15,000 RPM for 3 minutes. The supernatant was then removed, and isopropanol was added to precipitate genomic DNA, following which the sample was centrifuged at 15,000 RPM for 2 minutes at $4^{\circ} \mathrm{C}$. The supernatant was then drained, and the DNA pellet was washed with $70 \%$ ethanol, followed by centrifugation at 15,000 RPM for 1 minute. The DNA pellet was then resuspended in DNA hydration solution, incubated at $65^{\circ} \mathrm{C}$ for 1 hour to dissolve DNA, and then incubated at $22^{\circ} \mathrm{C}$ for 1 hour. This precipitated DNA was used as a template in a PCR reaction using TP53-specific primers flanking the A159 and P153 residues. The PCR amplicon was ligated into a $\mathrm{PCR}^{\mathrm{TM}} 4-\mathrm{TOPO}{ }^{\mathrm{TM}}$ blunt cloning vector, and the ligation mix was transformed into DH5 $\alpha$ chemically competent cells. Plasmid DNA was isolated from transformed colonies and sequenced using M13 primers.

\section{Luciferase assay}

Stable SaOS2 cell lines harboring pCW57.1 plasmid (either empty vector or pCW57.1 with the appropriate TP53 allele cloned into it) were first treated with $2 \mu \mathrm{g} / \mathrm{ml}$ Dox for 2 days to induce TP53 expression, which were then transfected with a combination of PG13-luc assay plasmid and a control plasmid pRL-SV40P (50:1) using Lipofectamine 2000 (Invitrogen, USA) in accordance with the manufacturer's instructions. After 48h of transfection, cell lysates were prepared and firefly and Renilla luciferase activities were measured by using the Dual-luciferase assay system according to the manufacturer's instructions (Promega). All values are mean \pm SD from at least three independent experiments. Significance was calculated by one-way ANOVA with Dunnett's multiple comparisons tests. This assay was performed using technical triplicates, with 3 biological replicates completed. 


\section{Caspase Glo 3/7 assay}

SaOS 2 cells were seeded at $20 \%$ confluency in 24 -well plates and placed in the Incucyte, with half of the wells treated with $2 \mu \mathrm{g} / \mathrm{ml}$ Dox for two days to induce p53 expression. After reaching $\sim 40 \%$ confluency, media was supplemented with Caspase-Glo 3/7 reagent (1:1,000, Essen Bioscience) and Nuclight reagent (1:500, Essen Bioscience). Images of wells with and without Dox treatment were acquired at 24h post Caspase 3/7 in wellstaining and processed using Adobe Photoshop and analyzed using ImageJ Cell Counter to determine percent caspase 3/7 events. Significance was determined using a two-way ANOVA with Sidak's multiple comparisons test. This assay was performed in biological triplicates, using 3 technical replicates per assay.

\section{ZMC1 treatment}

Tumor-bound fish were incubated in fish water containing ZMC1 at $70 \mathrm{nM}$ concentration with another batch of tumor-bound fish incubated in $0.1 \% \mathrm{v} / \mathrm{v}$ DMSO (diluted in fish water) as control. Fish were imaged every week on an Olympus MVX10 stereomicroscope with an X-Cite series 120Q fluorescence illuminator and size of tumors was measured from the acquired images using FIJI software.

\section{Homology Modeling}

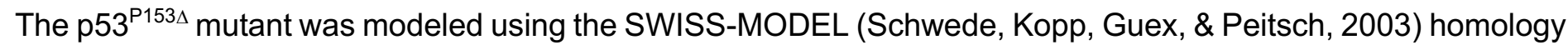
modeling server. The mutant $\mathrm{p} 53$ sequence and the $\mathrm{p} 53^{\mathrm{WT}}$ crystal DNA-binding domain crystal structure $2 \mathrm{XWR}$ (Natan et al., 2011) were used as input files. The homology models are built, scored and selected using statistical potentials of mean force scoring methods. Side-chain rotomers for non-conserved residues are selected through a local energy minimization function and the final models are subjected to global energy minimization using the CHARM22/CMAP forcefield (Waterhouse et al., 2018).

\section{Author contributions}

$\mathrm{JC}$ and KB performed and/or interpreted or supervised aspects of the different experiments and helped write the manuscript; $\mathrm{NH}, \mathrm{LW}, \mathrm{AL}, \mathrm{AC}, \mathrm{DL}$ and $\mathrm{AB}$ helped with different experiments and analysis; $A B$ and $D S L$ provided structural analyses for the $\mathrm{p} 53^{\mathrm{P} 153 \Delta}$ mutant. EYC and AG both soft tissue pathologists, helped with histology and immunohistochemistry analysis. PH, GT, AS, and AL discussed the clinical importance of the 
results. MI provided overall study direction, funding, and writing of the manuscript. All authors critically reviewed the report and approved the final version.

\section{Grant Support}

This project has been funded with federal funds from NIH grants MI and PH (R00CA175184), Cancer

Prevention \& Research Institute of Texas (CPRIT)-funded Scholar grant to MI (RR160062). JC was supported in part by the Wenzhou Medical University young scientist training program (2018). MI is a recipient of the Max and Minnie Tomerlin Voelcker Fund Young Investigator Award. DSL is supported by the St. Baldricks Foundation and the Welch Foundation. DSL and MI are each recipients of the Max and Minnie Tomerlin Voelcker Fund Young Investigator Awards. Kunal Baxi is a T32 and TL1 fellow (T32CA148724, TL1TR002647). Nicole Hensch was supported by Greehey CCRI Graduate Student Fellowship. Amanda Lipsitt was supported by Cancer Prevention \& Research Institute of Texas (CPRIT)-funded Research Training Award (RP 170345) and by a Hyundai Hope On Wheels Young Investigator Grant.

\section{Declaration of Interests}

The authors declare that they have no conflict of interest. 


\section{Figures and Figure Legends:}

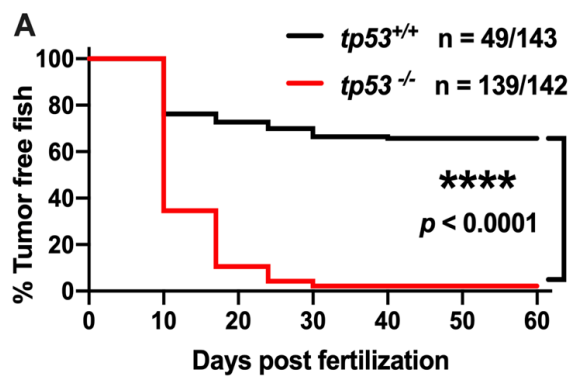

B
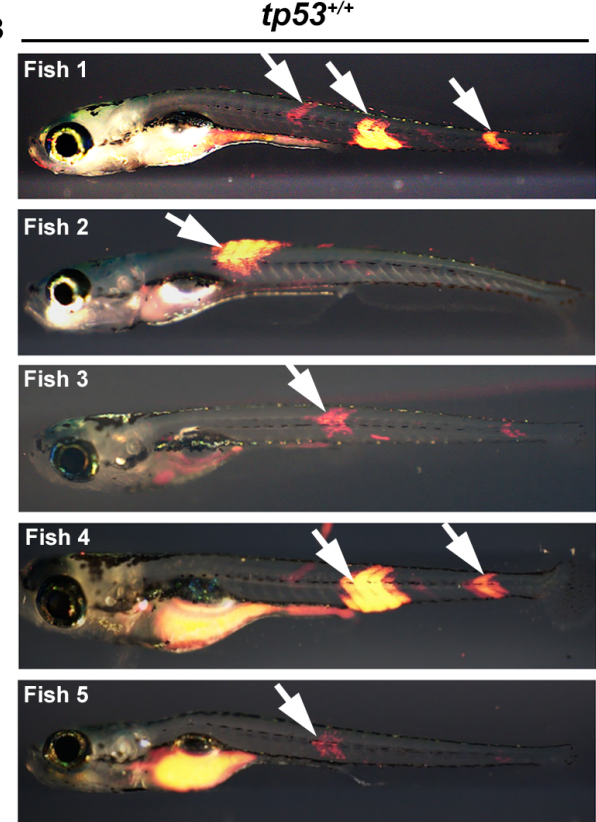

$\mathbf{F}$



$\operatorname{tp53}^{-/-}$
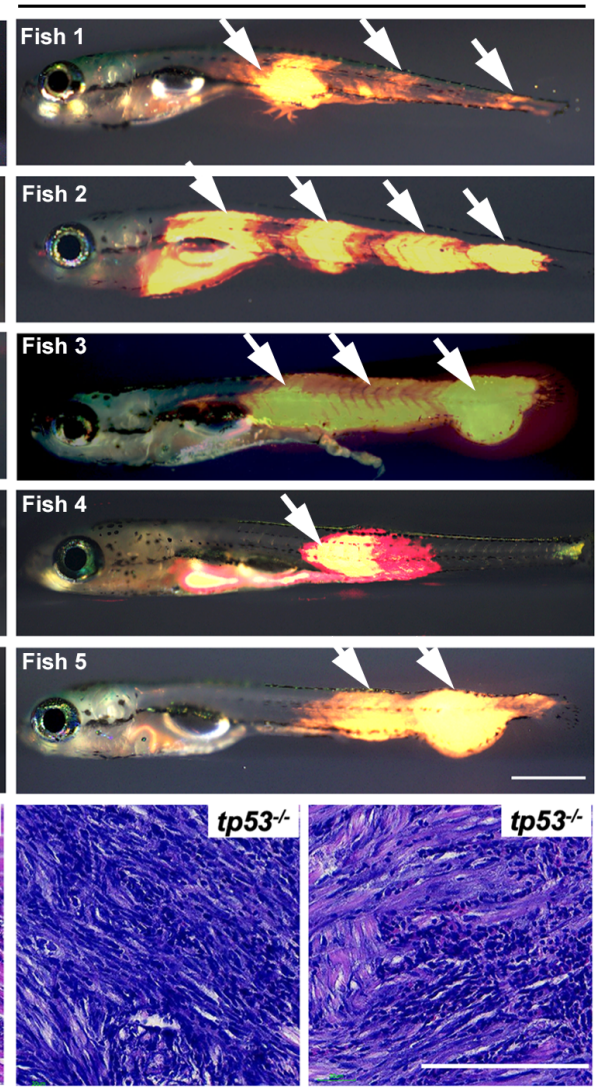

Figure 1: tp53 suppresses ERMS tumor initiation

(A) Kaplan-Meier plot showing ERMS tumor initiation in $t p 53^{-/-}$and $t p 53^{+/+}$fish.

(B) Representative images of DsRed-positive zebrafish ERMS. Arrows show tumor location for each fish. Scale bar $=1 \mathrm{~mm}$.

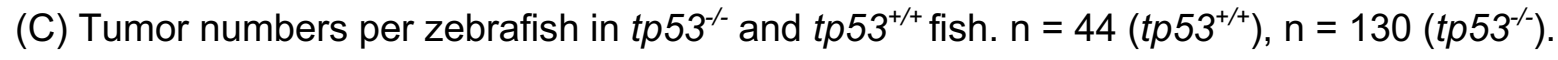

(D) Ratio of tumor area to total body area in in $t p 53^{-/-}$and $t p 53^{+/+}$fish. $\mathrm{n}=10$.

(E) Pie chart showing percentage of tumors found in varying regions of $t p 53^{-/}$and $t p 53^{+/+}$fish, showing no significant differences in tumor localization. Head $-p=0.25848$, trunk $-p=0.39532$, tail $-p=0.92034$ (Twotailed Two Proportions Z test).

(F) Representative H\&E staining of zebrafish ERMS tumors. Scale bar $=100 \mu \mathrm{m}$. 

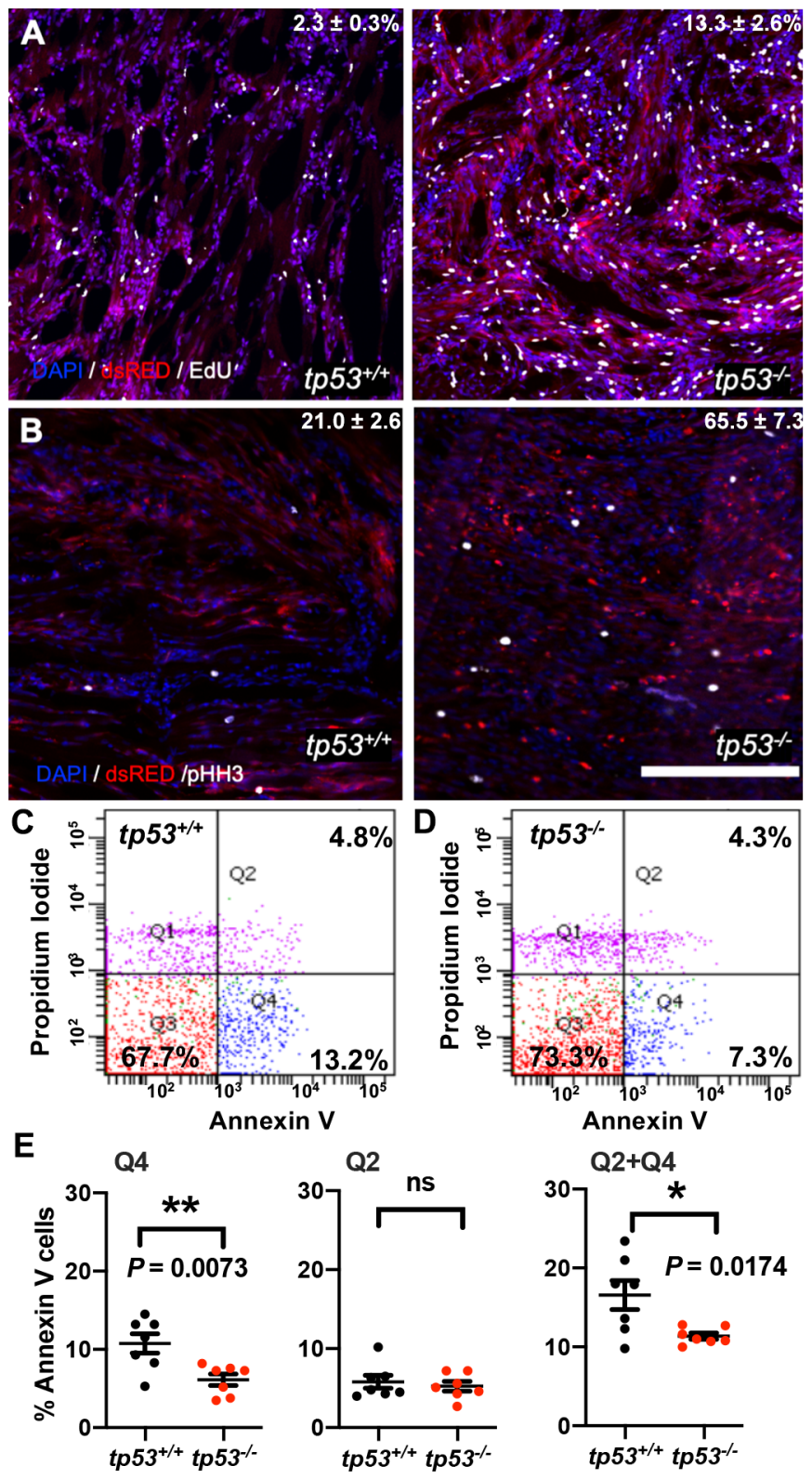

Figure 2: tp53 is a potent suppressor of proliferation and to a lesser extent of apoptosis

(A) Representative confocal microscopy images of EdU staining on ERMS tumor sections $n=13 \sim 16$.

(B) Representative confocal microscopy images of phospho-histone H3 staining on ERMS tumor sections. (Scale bar $=100 \mu \mathrm{m}) \mathrm{n}=6$.

(C, D) Representative flow cytometry analysis of Annexin $\mathrm{V}$ staining of $t p 53^{+/+}$and $t p 53^{-/}$ERMS tumors, respectively. 
bioRxiv preprint doi: https://doi.org/10.1101/2021.04.21.440757; this version posted April 22, 2021. The copyright holder for this preprint (which was not certified by peer review) is the author/funder, who has granted bioRxiv a license to display the preprint in perpetuity. It is made available under aCC-BY 4.0 International license.

(E) Quantification of flow cytometry analysis of Annexin V staining. Q1 = Pre-necrotic cells, Q2 = late apoptosis

+ necrotic cells, $\mathrm{Q} 3=$ living cells, $\mathrm{Q} 4=$ early apoptotic cells. $\mathrm{n}=7 . \mathrm{ns}=$ not significant, $p=0.5926$, Unpaired $\mathrm{t}$

test. 


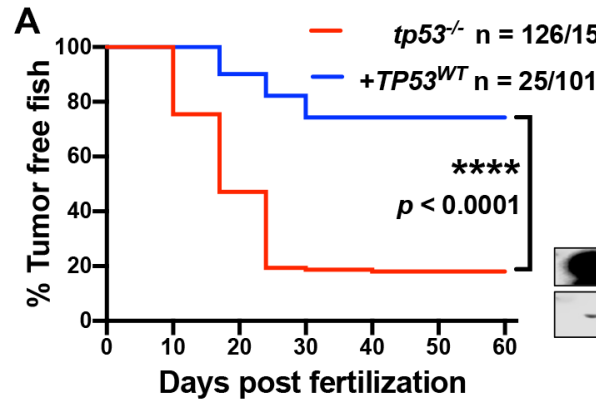

B
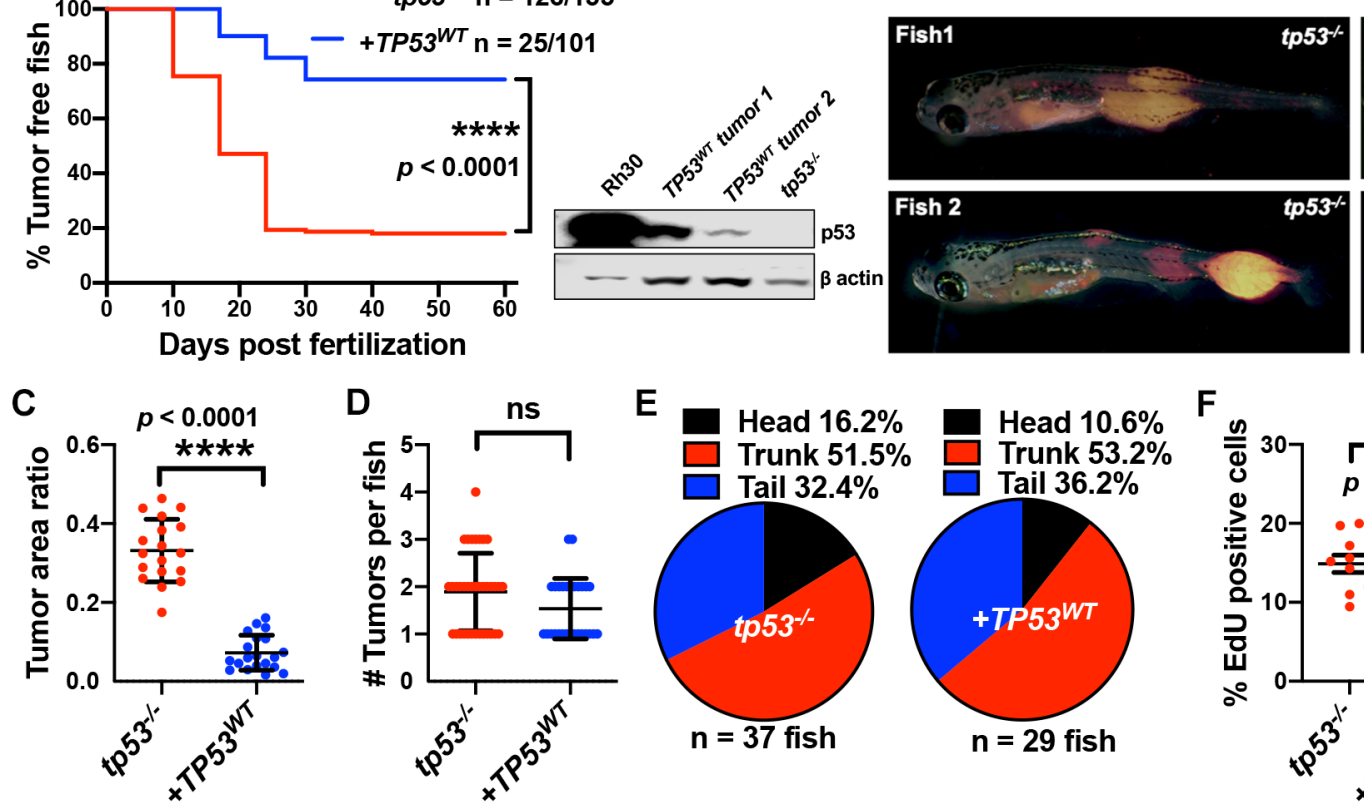

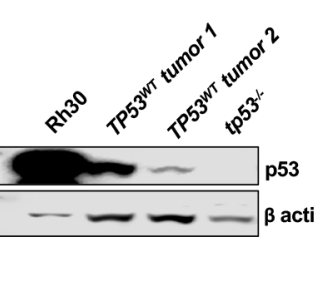

E

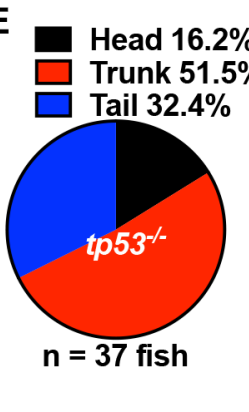

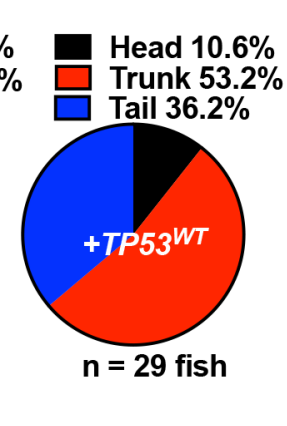

$+T P 53 W T$

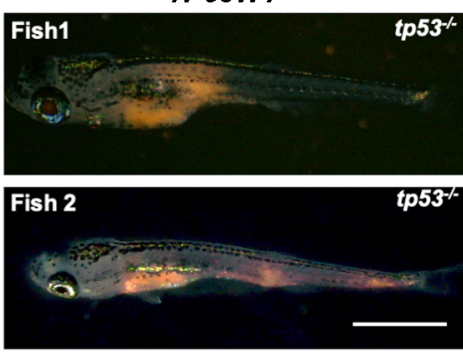

G

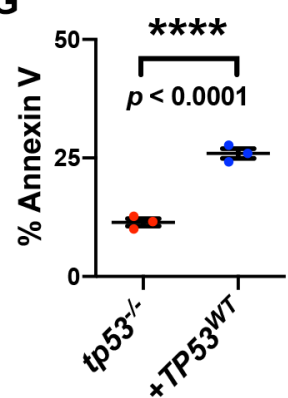

Figure 3: Human TP53 blocks tumor initiation, growth, and proliferation and increases apoptosis in tp53-

\section{I- zebrafish}

(A) Kaplan-Meier plot showing ERMS tumor initiation in $t p 53^{-/-}$fish with or without $p 53^{\mathrm{WT}}$ expression. Western Blot analysis was performed to assess $\mathrm{p} 53^{\mathrm{WT}}$ expression level in tumors.

(B) Representative images of ERMS tumors in $t p 53^{-/-}$fish with or without human TP53 ${ }^{W T}$ expression.

(C) Ratio of tumor area to total body area in $t p 53^{-/-}$fish with or without expression of $T P 53^{W T}$. $\mathrm{n}=18$.

(D) Number of tumors per $t p 53^{--}$zebrafish with or without expression of $T P 53^{W T}$. ns $=$ not significant. $\mathrm{n}=36$ $\left(t p 53^{-/-}\right), \mathrm{n}=28\left(T P 53^{W T}\right)$.

(E) Pie chart showing site of tumor localization in $t p 53^{-/}$fish with or without expression of $T P 53^{W T}$ showing no statistical differences. Head $-p=0.20045$, trunk $-p=0.42858$, tail $-p=0.3336$. Quantification of proliferation $(F)$ and apoptosis $(G)$ via EdU staining $(n=10)$ and Annexin $V$ staining $(n=3)$, respectively, for tumors arising in $t p 53^{-/}$fish with or without expression of TP53 ${ }^{W T}$. 


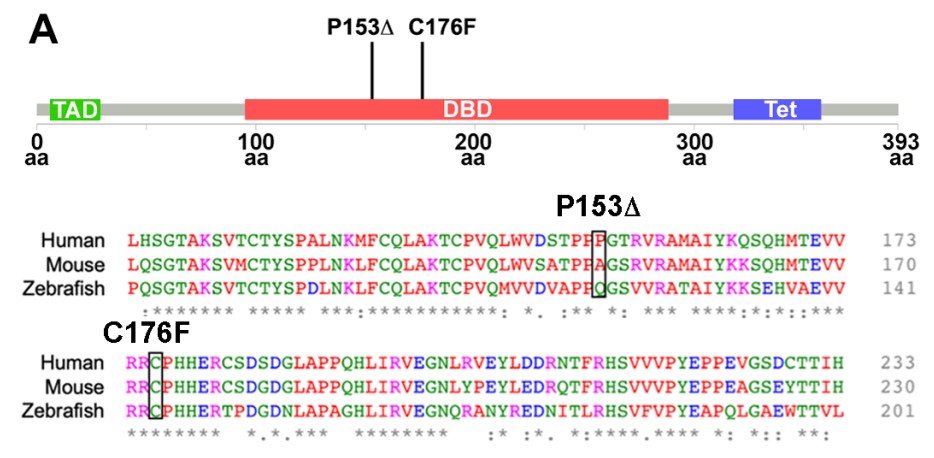

B
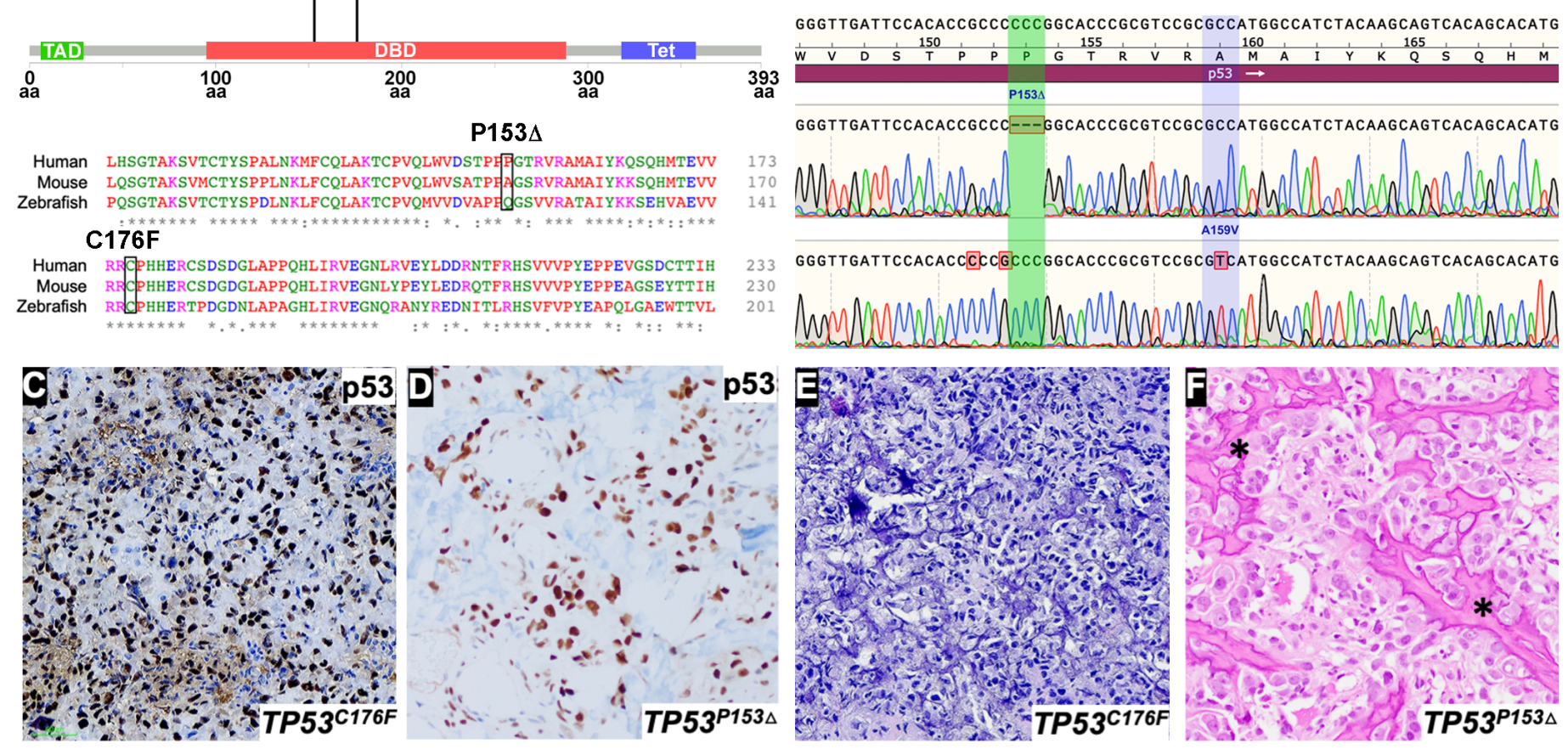

G


L

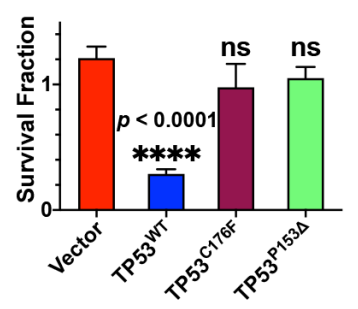

M

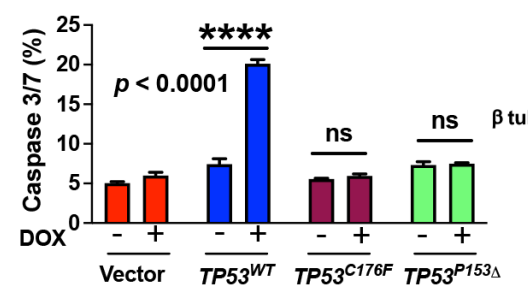

N

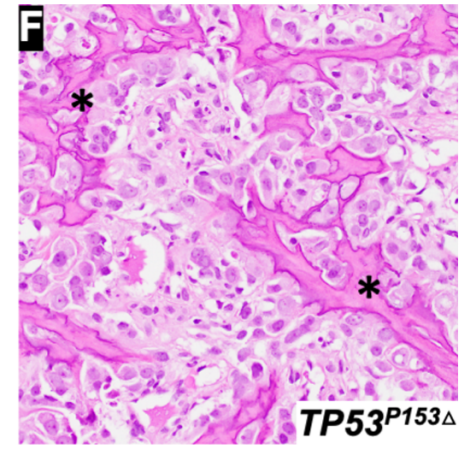

$\mathbf{J}$
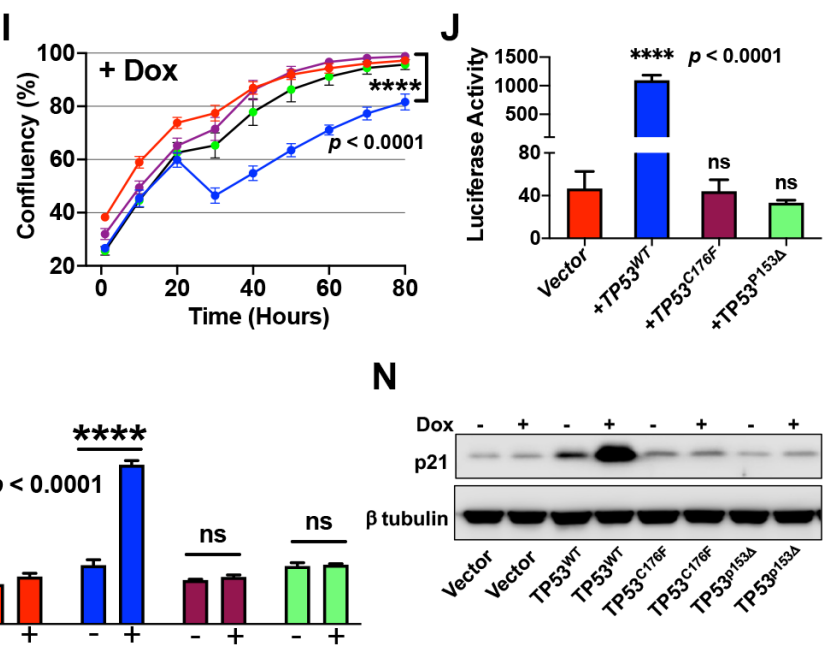

Figure 4: Assigning pathogenicity to two novel human TP53 sarcoma mutations

(A) Lollipop plot showing the two novel, human TP53 mutations P153 and C176F, as well as the amino acid sequence alignment for human, mouse, and zebrafish protein.

(B) DNA sequencing data from osteosarcoma patient confirming the germline P153 $\Delta$ mutation, as well as somatic A159V mutation.

(C, D) p53 immunohistochemistry staining of p53 in ERMS PDX SJRHB00011 expressing p53 ${ }^{\mathrm{C} 176 \mathrm{~F}}$ and osteosarcoma expressing $\mathrm{p} 53^{\mathrm{P} 153 \Delta}$. 
(E, F) Representative H\&E staining of ERMS PDX expressing the C176F mutation and diagnostic biopsy of osteosarcoma tumor expressing osteosarcoma expressing $\mathrm{p} 53^{\mathrm{P} 153 \Delta}$ showing neoplastic tumor cells with pleomorphic nuclei, irregular chromatin pattern, as well as irregular disorganized trabeculae of unmineralized malignant osteoid (stars).

(G) Expression of $\mathrm{p} 53^{\mathrm{WT}}$, as well as $\mathrm{p} 53^{\mathrm{C} 176 \mathrm{~F}}$ and $\mathrm{p} 53^{\mathrm{P} 153 \Delta}$ mutant protein, from a Dox-inducible pCW57.1 vector in SaOS2 osteosarcoma cells.

$(\mathrm{H}, \mathrm{I})$ Growth curves (\% confluence) of osteosarcoma SaOS2 cells harboring Dox-inducible pCW57.1 vector in the absence and presence of Dox, respectively. ns = not significant.

(J) Luciferase assay to assess mutant p53 transcriptional activity. ns = not significant.

(K) Colony forming assay in osteosarcoma SaOS2 cells harboring Dox-inducible pCW57.1 with either mutant or WT TP53 in the absence or presence of Dox, respectively.

(L) Quantification of change in colony formation in J. ns = not significant.

(M) Quantification of apoptosis in osteosarcoma SaOS2 cells harboring Dox-inducible pCW57.1 with either mutant or WT TP53 in the absence or presence of Dox. ns = not significant.

(N) p21 expression in SaOS2 cells harboring Dox-inducible pCW57.1 with either WT or mutant p53 in the presence or absence of Dox. 

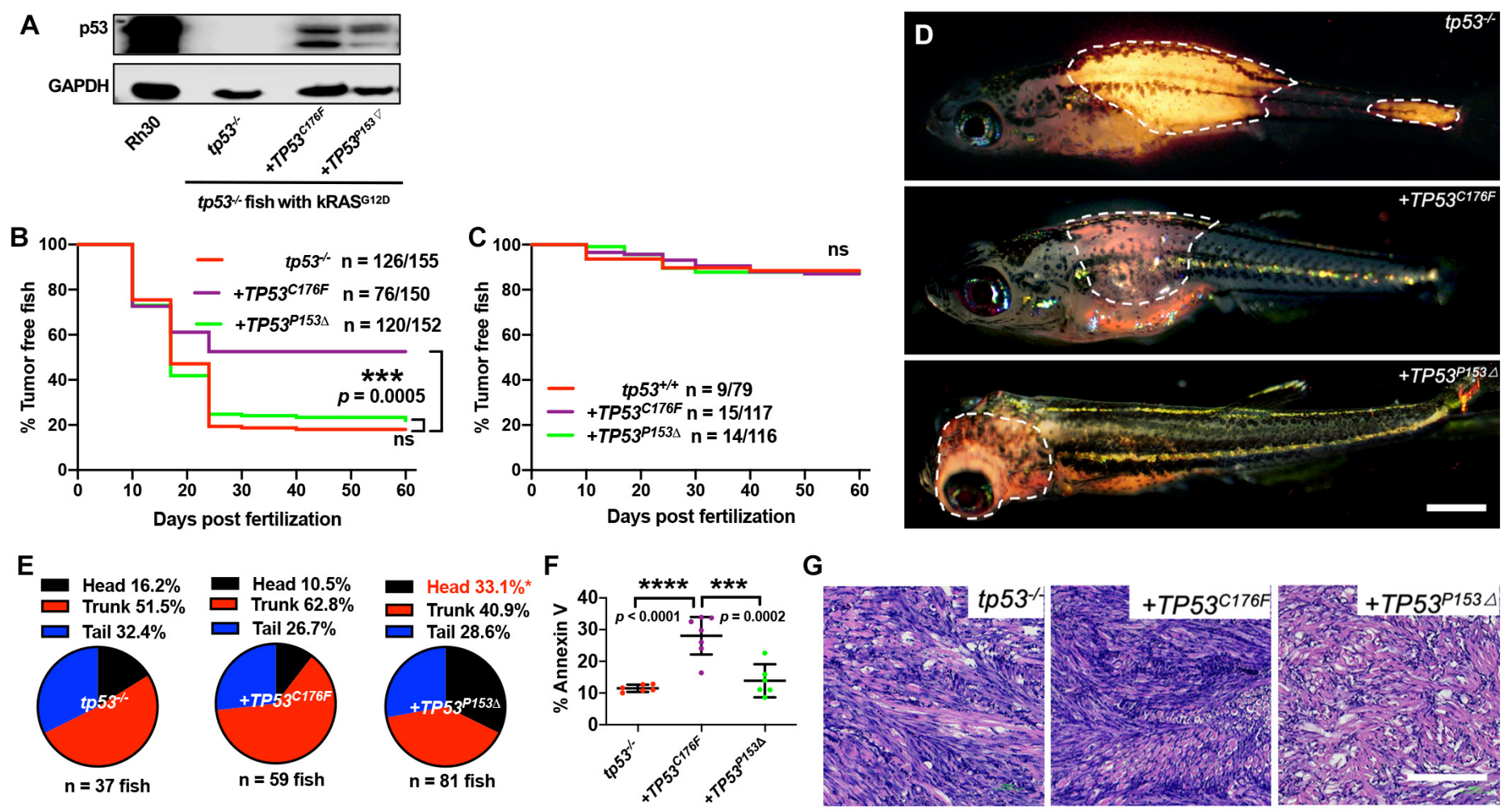

Figure 5: Assigning pathogenicity to two novel gain-of-function TP53 mutations in tp53\% zebrafish

(A) Protein expression of mutant p53 in zebrafish ERMS tumors, with RMS cell line, Rh30, as a control.

(B) Kaplan-Meier plot showing tumor initiation in $t p 53^{-/-}$fish with or without expression of mutant TP53.

(C) Kaplan-Meier plot showing tumor initiation in $t p 53^{+/+}$fish with or without expression of mutant TP53. ns $=$not significant

(D) Representative images of tumor localization in $t p 53^{-/-}$fish with or without expression of mutant TP53.

(E) Pie chart showing percentage of tumors found in varying regions of $t p 53^{-/-}$fish with or without expression of mutant TP53. Percentages in red indicate a significant difference to $t p 53^{-/}(p=0.0096$, Two-tailed Two Proportions Z test).

(F) Quantification of Annexin V staining in tumors arising in tp53/- fish with or without expression of mutant TP53. $n=6-7$.

(G) Representative H\&E staining of tumors arising in $t p 53^{-/-}$fish with or without expression of mutant TP53. 

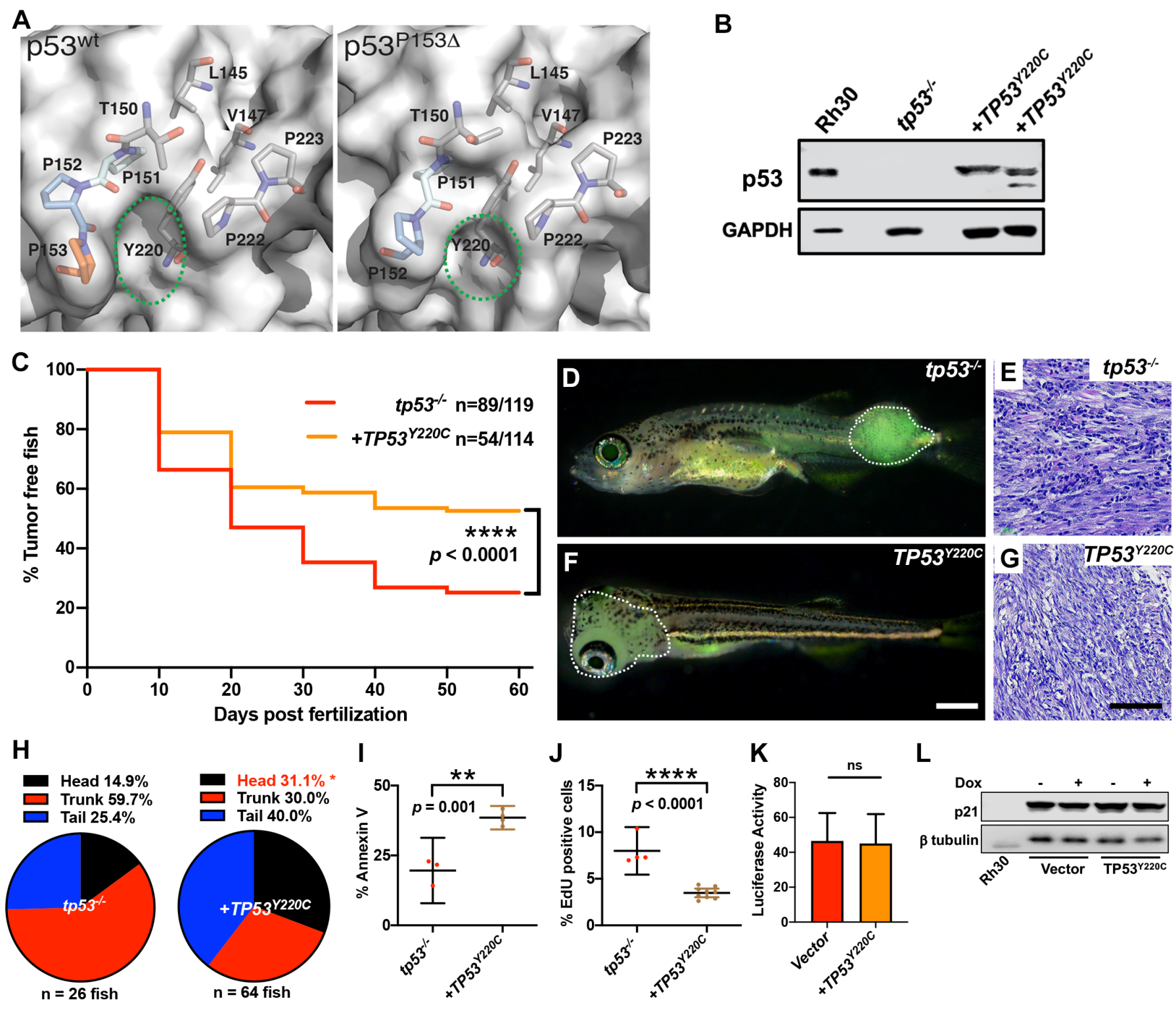

L

\section{Figure 6: $T P 53^{Y 220 C}$ predisposes to head ERMS in zebrafish}

(A) Surface representation of $\mathrm{p} 53^{\mathrm{WT}}$ (PDB 2XWR) and $\mathrm{p} 53^{\mathrm{P} 153 \Delta}$ (homology model) showing key residues lining a surface exposed pocket (sticks). The green ovals compare the size and shape of the pocket between the two structures.

(B) p53 protein expression levels in $t p 53^{-/}$fish tumors with or without TP53 ${ }^{\mathrm{Y} 220 \mathrm{C}}$, with RMS cell line, Rh30, as a control.

(C) Kaplan-Meier plot showing tumor initiation in $t p 53^{-/}$fish, with or without TP53 ${ }^{\mathrm{Y} 220 \mathrm{C}}$.

(D) and (F) Representative images of $t p 53^{--}$fish with ERMS tumors, with or without TP53 ${ }^{\mathrm{Y} 220 \mathrm{C}}$ (GFP positive).

Dashed region outlines the tumor.

(E) and (G) Representative H\&E staining of tumors in $t p 53^{-/-}$fish, with or without $T P 53^{\mathrm{Y} 220 \mathrm{C}}$. 
bioRxiv preprint doi: https://doi.org/10.1101/2021.04.21.440757; this version posted April 22, 2021. The copyright holder for this preprint (which

was not certified by peer review) is the author/funder, who has granted bioRxiv a license to display the preprint in perpetuity. It is made available under aCC-BY 4.0 International license.

(H) Pie chart showing localization of tumors expressed as a percentage found in varying regions of in tp5 $3^{-/}$fish

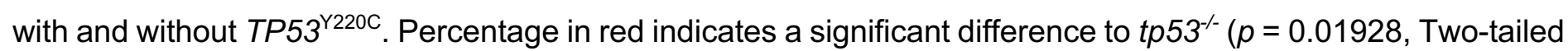
Two Proportions Z test).

(I) Quantification of Annexin V staining in tumors of $t p 53^{-/-}$fish with or without expression of TP53 ${ }^{\mathrm{Y} 220 \mathrm{C}} . \mathrm{n}=3-4$.

(J) Quantification of EdU staining in tumors of $t p 53^{-/-}$fish with or without expression of TP53 ${ }^{Y 220 C} . \mathrm{n}=4-9$.

(K) Luciferase assay to assess mutant p53 transcriptional activity. ns = not significant.

(L) p21 protein expression in SaOS2 cells harboring Dox-inducible pCW57.1 Vector only or expressing TP53 ${ }^{\text {Y220C }}$ in the presence or absence of Dox, with RMS cell line, Rh30, as a control. 


\section{Supplemental Figures:}

A

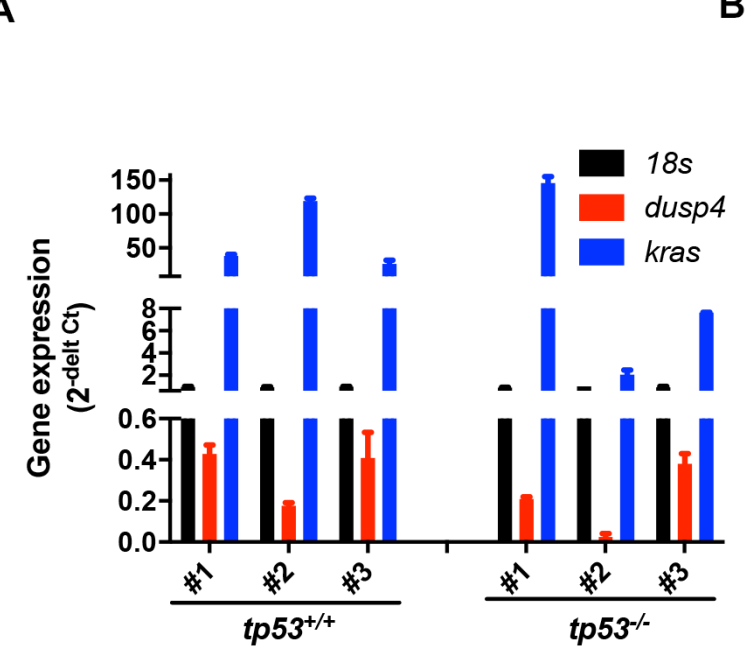

C
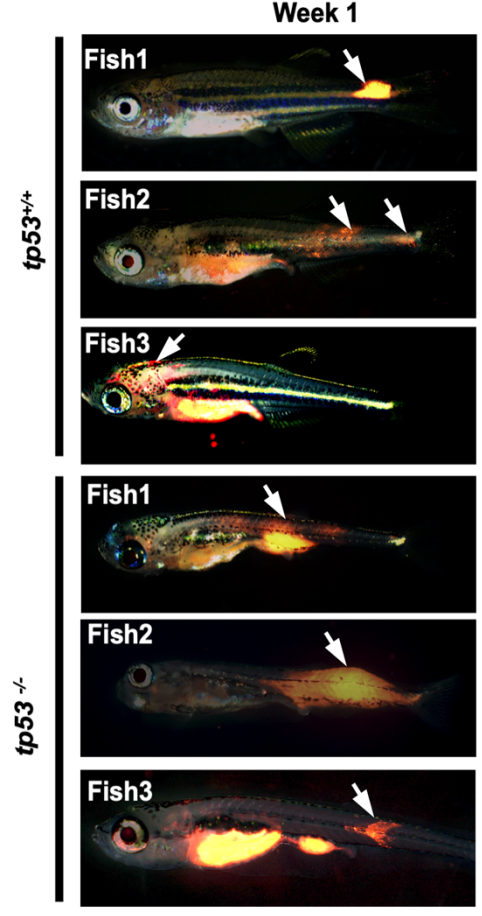

B

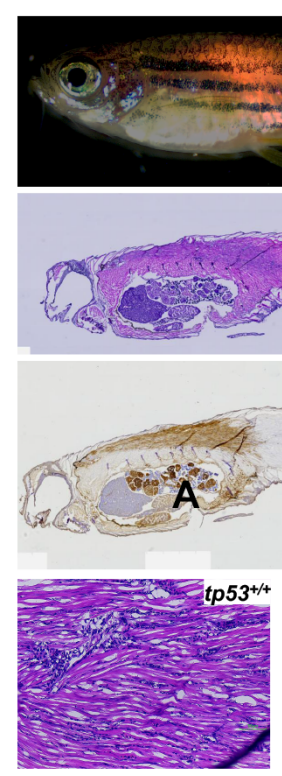

$\operatorname{tp} 53^{+/+}$
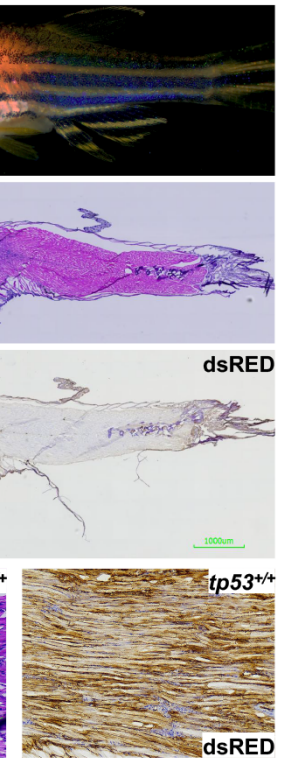
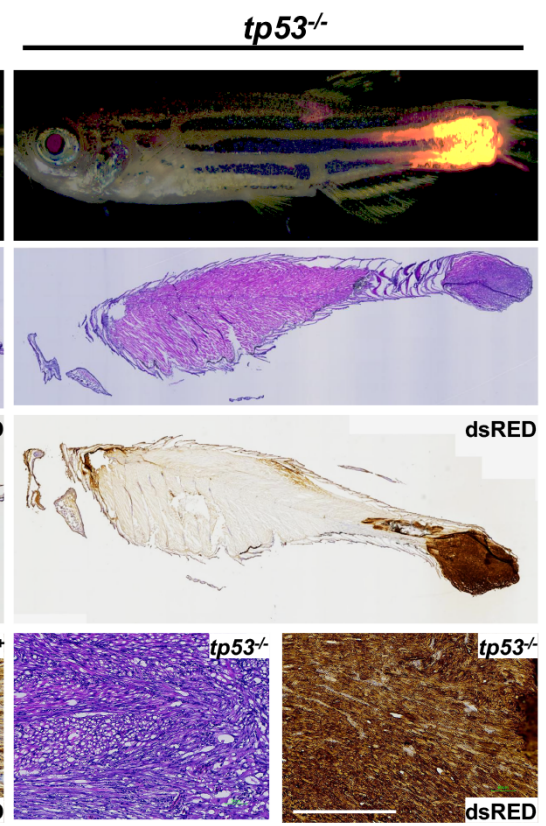

D


\section{Figure S1:}

(A) mRNA expression of $k R A S^{G 12 D}$ and dusp4 in compared to $18 \mathrm{~s}$ expression level.

(B) Representative H\&E and immunohistochemistry (anti-DsRed) staining in ERMS tumor fish. Arrows denote location of tumors. 
bioRxiv preprint doi: https://doi.org/10.1101/2021.04.21.440757; this version posted April 22, 2021. The copyright holder for this preprint (which was not certified by peer review) is the author/funder, who has granted bioRxiv a license to display the preprint in perpetuity. It is made available under aCC-BY 4.0 International license.

(C) Assessment of tumor growth and proliferation over 3 weeks in $t p 53^{-/}$and $t p 53^{+/+}$fish (3 representative fish per group). Scale bar $=0.5 \mathrm{~mm}$.

(D) Representative H\&E staining of $t p 53^{-/}$and $t p 53^{+/+}$tumors. Scale bar $=100 \mu \mathrm{m}$.

(E) Tumor size ratio per animal calculated over 3 weeks for $t p 53^{-/-}$and $t p 53^{+/+}$fish. ns $=$not significant. $n=13-$

16. 
A



B

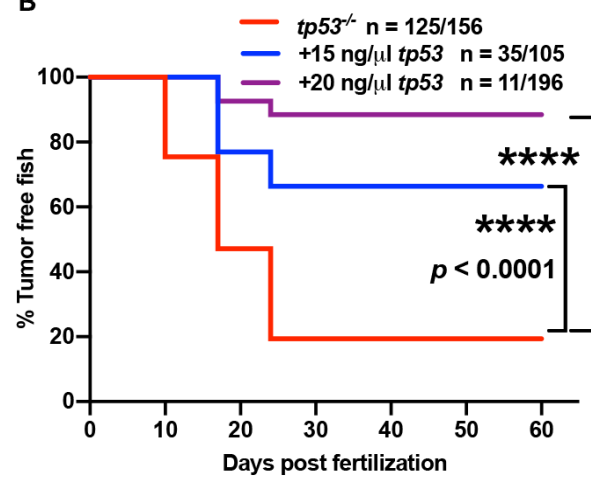

C

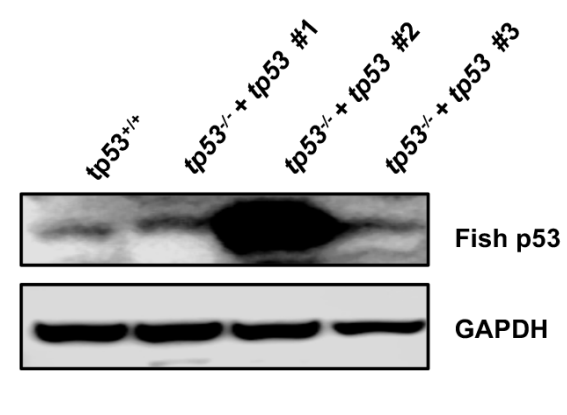

Figure S3:

(A) Kaplan-Meier plot showing ERMS tumor initiation in $t p 53^{+/+}$fish (AB WT strain) with or without $p 53^{W T}$. ns $=$ not significant

(B) Kaplan-Meijer plot showing ERMS tumor initiation in tp53\%-- fish (AB WT strain) with or without tp53.

(C) Zebrafish p53 expression levels in three tp53/-- tumors expressed rag2-tp53 along with rag2-kRAS ${ }^{G 12 D}$, using AB WT tumor driven by rag2-kRAS ${ }^{G 12 D}$ as control. 
A

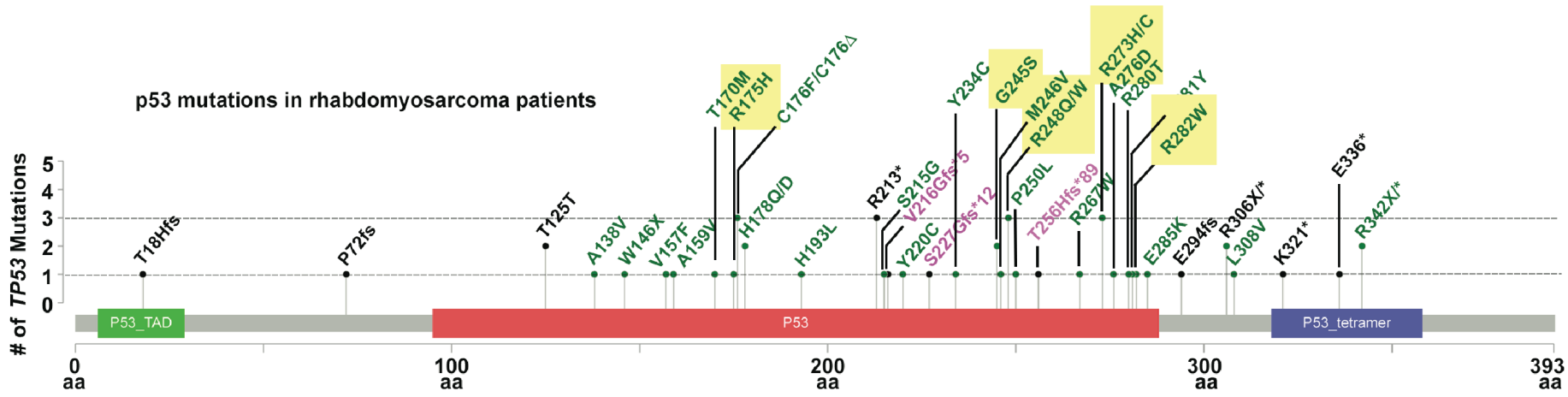

B

Human

Chimpanzee

Hamster (CHO)

Guinea Pig

Rat

Rabbit

Red Squirrel

Lemur

Blue Whale

Cow

Cat

Dog

Mouse

Zebrafish
SGTAKSVTCTYSPALNKMFCQLAKTCPVQLWVDSTPPPGTRVRAMAIYKQSQHMTEVVRR 175

SGTAKSVTCTYSPALNKMFCQLAKTCPVQLWVDSTPPPGTRVRAMAIYKQSQHMTEVVRR 175

SGTAKSVTCTYSPSLNKLFCQLAKTCPVQLWVNSTPPPGTRVRAMAIYKKLQYMTEVVRR 175

SGTAKSVTCTYSPGLNKLFCQLAKTCPVQVWVESPPPPGTRVRALAIYKKSQHMTEVVRR 173

SGTAKSVMCTYSISLNKLFCQLAKTCPVQLWVTSTPPPGTRVRAMAIYKKSQHMTEVVRR 173

SGTAKSVTCTYSPCLNKLFCQLAKTCPVQLWVDSTPPPGSRVRAMAIYKKSOHMTEVVRR 172

SGTAKSVTCTYSPSLNKLFCQLAKTCPVQLWVDSTPPPGTRVRAMAIYKKSOHMTEVVRR 172

SGTAKSVTCTYSPALNKMFCQLAKTCPVQLWVDSMPPPGSRIRAMAIYKQSQHMTEVVRR 171

SGTAKSVTCTYSPALNKLFCQLAKTCPVQLWVSSPPPPGTRVRAMAIYKKSEYMTEVVRR 168

SGTAKSVTCTYSPSLNKLFCQLAKTCPVQLWVDSPPPPGTRVRAMAIYKKLEHMTEVVRR 167

SGTAKSVTCTYSPPLNKLFCQLAKTCPVQLWVRSPPPPGTCVRAMAIYKKSEFMTEVVRR 167

SGTAKSVTWTYSPLLNKLFCQLAKTCPVQLWVSSPPPPNTCVRAMAIYKKSEFVTEVVRR 162

SGTAKSVMCTYSPPLNKLFCQLAKTCPVQLWVSATPPAGSRVRAMAIYKKSQHMTEVVRR 172

SGTAKSVTCTYSPDLNKLFCQLAKTCPVQMVVDVAPPQGSVVRATAIYKKSEHVAEVVRR

\section{Figure S4:}

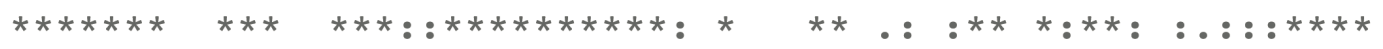

(A) Lollipop plot showing common TP53 mutations in Rhabdomyosarcoma patients as well as the seven most common TP53 hot spot mutations across all cancers.

(B) The amino acid sequence alignment for $T P 53^{P 153}$ with other species. The yellow highlight the amino acid of P153, and the top panel showed the conserved ones and bottom five species showed the non-conserved ones. 

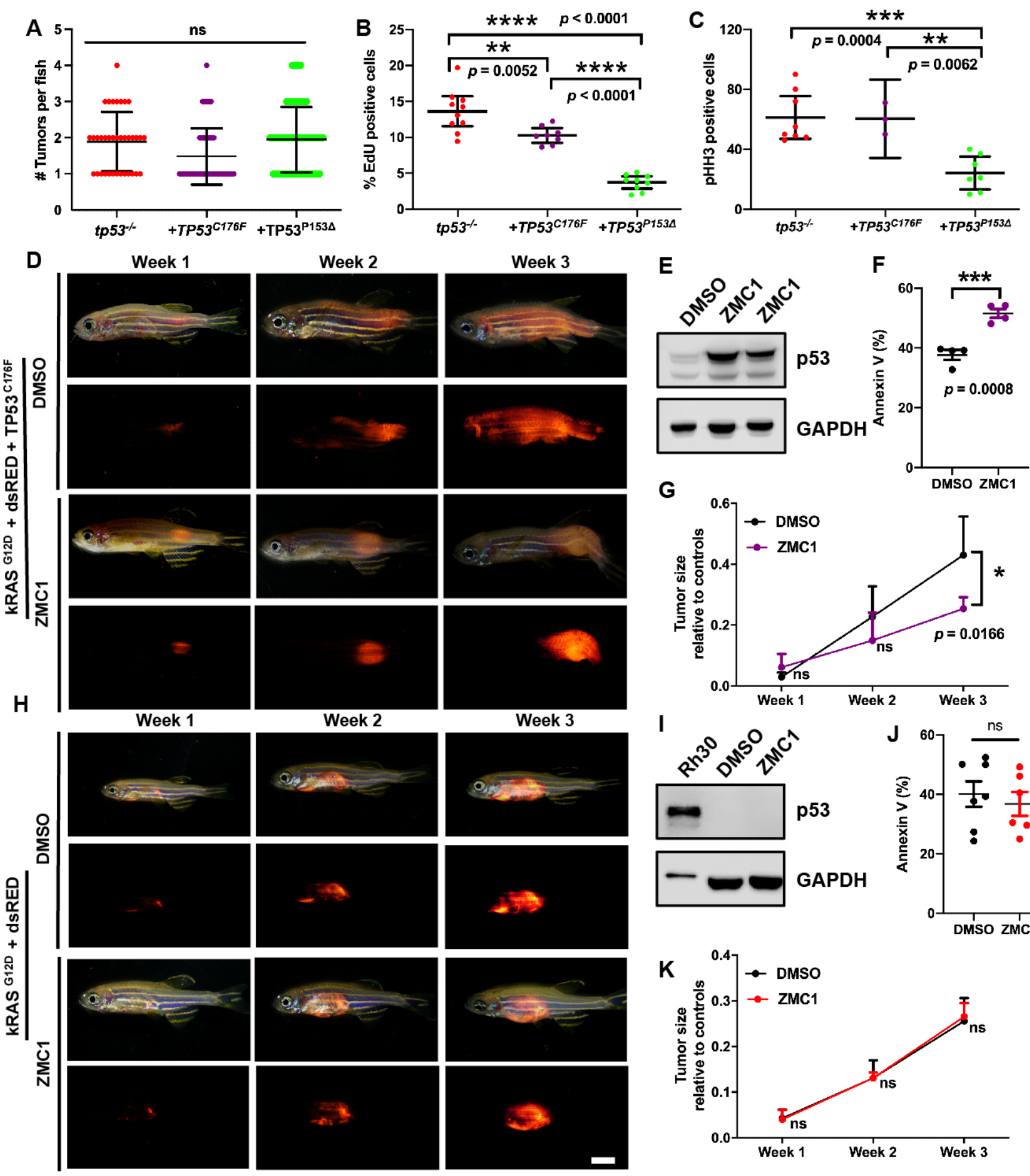

G
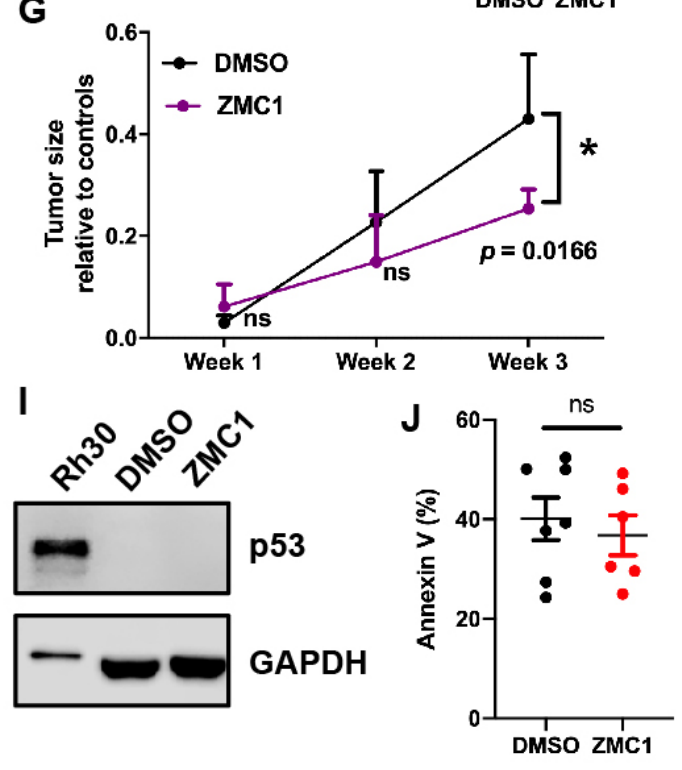

\section{Figure S5:}

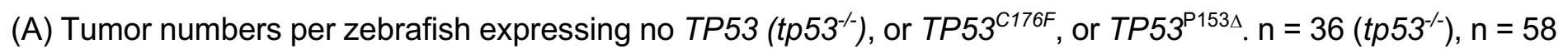
$\left(\right.$ TP53 $\left.{ }^{C 176 F}\right), \mathrm{n}=81\left(\right.$ TP53 $\left.^{\mathrm{P} 153 \Delta}\right)$. 
bioRxiv preprint doi: https://doi.org/10.1101/2021.04.21.440757; this version posted April 22, 2021. The copyright holder for this preprint (which

was not certified by peer review) is the author/funder, who has granted bioRxiv a license to display the preprint in perpetuity. It is made available under aCC-BY 4.0 International license.

(B) Percentage of EdU positive cells in representative areas of fish tumors expressing either no TP53 (tp53-/), TP53 ${ }^{C 176 F}$, or TP53 ${ }^{P 153 \Delta} \cdot \mathrm{n}=8-10$.

(C) Number of phospho-histone H3 positive cells in representative areas of fish tumors expressing either no

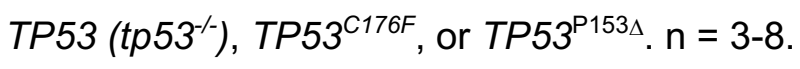

(D) Representative images of tumor burdened zebrafish with tumors expressing $k R A S^{G 12 D}+T P 53^{C 176 F}(\mathrm{DsRed}+)$ treated with either DMSO or ZMC1 over a span of 3 weeks.

(E) Western Blot showing p53 expression levels in fish tumors expressing $k R A S^{G 12 D}+T P 53^{C 176 F}$ and treated with either DMSO or ZMC1.

(F) Percentage of Annexin $V$ positive cells in tumors expressing $k R A S^{G 12 D}+T P 53^{C 176 F}$ that were treated with either DMSO or ZMC1. $\mathrm{n}=4$.

(G) Ratio of tumor size to total body for in fish tumors expressing $k R A S^{G 12 D}+T P 53^{C 176 F}$, treated with either DMSO or ZMC1. $\mathrm{ns}=$ not significant, $\mathrm{n}=4$.

$(H)$ Representative images of tumor burdened zebrafish expressing $k R A S^{G 12 D}$ (DsRed+) treated with either DMSO or ZMC1 over a span of 3 weeks.

(I) Western Blot showing p53 expression levels in Rh30 cells (control) and fish tumors expressing $k R A S^{G 12 D}$, treated with either DMSO or ZMC1.

(J) Percentage of Annexin V staining of fish tumors expressing $k R A S^{G 12 D}$, treated with either DMSO or ZMC1. ns $=$ not significant. $\mathrm{n}=6-7$.

(K) Ratio of tumor size to total body in tumors expressing $k R A S^{G 12}$, treated with either DMSO or ZMC1. ns = not significant, $n=4$. 



Figure S6:

(A) Tumor numbers per zebrafish tumor expressing either no TP53 $\left(\right.$ tp $\left.53^{-/-}\right)$, or TP53 ${ }^{\Upsilon 220 C} \cdot \mathrm{n}=89\left(\operatorname{tp} 53^{-/-}\right), \mathrm{n}=54$ $\left(T P 53^{Y 220 C}\right)$.

(B) Representative images showing variation in tumor localization in fish expressing mutant TP53 (either DsRed positive or GFP positive).

(C) Protein expression of $\mathrm{p} 53^{\mathrm{Y} 220 \mathrm{C}}$ expressed from a dox-inducible pCW57.1 vector in SaOS2 cells, using Rh30 as a positive control. 
bioRxiv preprint doi: https://doi.org/10.1101/2021.04.21.440757; this version posted April 22, 2021. The copyright holder for this preprint (which was not certified by peer review) is the author/funder, who has granted bioRxiv a license to display the preprint in perpetuity. It is made available under aCC-BY 4.0 International license.

(D) Growth curves (\% confluence) of SaOS2 cells harboring dox-inducible pCW57.1 vector with or without $T P 53^{\mathrm{Y} 220 C}$ in the presence and absence of dox. ns = not significant

(E) Colony formation assay for SaOS2 cells harboring dox-inducible pCW57.1 vector with or without TP53 ${ }^{\text {Y220C }}$ in the presence and absence of dox.

(F) Quantification of caspase 3/7 assay to measure apoptosis for SaOS2 cells harboring dox-inducible pCW57.1 vector with or without $T P 53^{Y 220 C}$ in the presence and absence of dox. ns = not significant 
Table 1: List of Primers used in this study.

\begin{tabular}{|l|l|}
\hline \multicolumn{1}{|c|}{ Name } & \multicolumn{1}{c|}{ Sequence } \\
\hline 18s-QRT-1-F & TCGCTAGTTGGCATCGTTTATG \\
\hline 18s-QRT-1-R & CGGAGGTTCGAAGACGATCA \\
\hline hKRAS-QRT-F-137 & TTGATGGAGAAACCTGTCTCTTGG \\
\hline hKRAS-QRT-R-247 & CAAATACACAAAGAAAGCCTCCC \\
\hline dusp4-14F & ACGAACTTTGCGAAATGGAC \\
\hline dusp4-95R & CTGCAATCCAGAAGCAGACA \\
\hline TP53 fwd & CACCGTGTGCTGGAATCGGCTTA \\
\hline TP53P153 XO Rev & $\begin{array}{l}\text { GTAGATGGCCATGGCGCGGACGCGGGTGCCCGGGGGTGTGGAATCAACCCA } \\
\text { CAGCTGCAC }\end{array}$ \\
\hline TP53P153 XO Fwd & $\begin{array}{l}\text { GTGCAGCTGTGGGTTGATTCCACACCCCCGGGCACCCGCGTCCGCGCCATG } \\
\text { GCCATCTAC }\end{array}$ \\
\hline TP53 rev & ATCTGCAGAATTCGCTTTC \\
\hline TP53C176F XO Rev & $\begin{array}{l}\text { TCGCTATCTGAGCAGCGCTCATGGTGGGGGAAGCGCCTCACAACCTCCGTCA } \\
\text { TGTGTGTGAC }\end{array}$ \\
\hline TP53C176F XO Fwd & $\begin{array}{l}\text { GTCACAGCACATGACGGAGGTTGTGAGGCGCTTCCCCCACCATGAGCGCTGC } \\
\text { TCAGATAGCGA }\end{array}$ \\
\hline TP53Y220C XO Fwd & $\begin{array}{l}\text { CACTTTTCGACATAGTGTGGTGGTGCCCTGTGAGCCGCCTGAGGTTGGCTCT } \\
\text { GACTGTAC }\end{array}$ \\
\hline TP53Y220C XO Rev & $\begin{array}{l}\text { GTACAGTCAGAGCCAACCTCAGGCGGCTCACAGGGCACCACCACACTATGTC } \\
\text { GAAAAGTG }\end{array}$ \\
\hline
\end{tabular}

Table 2: List of antibodies used in this study.

\begin{tabular}{|l|l|l|}
\hline Antibody & Catalog No. & Vendor \\
\hline anti-DsRed antibody & 632496 & Takara Bio \\
\hline anti-p53 antibody (human) & ab1101 & Cell Signaling Technology \\
\hline anti-p53 antibody (fish) & ab77813 & Abcam \\
\hline anti-GAPDH antibody & 2118 & Cell Signaling Technology \\
\hline anti- $\beta$-actin antibody (human) & A00702-40 & GenScript \\
\hline anti-p21 antibody (human) & 2946 & Cell Signaling Technology \\
\hline anti- $\beta$-tubulin antibody (human) & ab6046 & Abcam \\
\hline anti-phosphohistoneH3 (Ser10) & $9701 S$ & Cell Signaling Technology \\
\hline
\end{tabular}

Table 3: List of reagents used in this study.

\begin{tabular}{|l|l|l|}
\hline & \multicolumn{1}{|c|}{$\begin{array}{c}\text { Catalog } \\
\text { No. }\end{array}$} & \multicolumn{1}{|c|}{ Vendor } \\
\hline Click-iT $^{\text {TM }}$ EdU Alexa Fluor ${ }^{\text {TM }}$ 647 Flow Cytometry Assay Kit & C10419 & ThermoFisher Scientific \\
\hline Annexin V, Alexa Fluor ${ }^{\text {TM } 647 \text { conjugate }}$ & A23204 & Invitrogen \\
\hline IncuCyte $®$ Caspase-3/7 Green Apoptosis Assay Reagent & 4440 & Sartorius \\
\hline ZMC1 & HY-18634 & MedChemExpress \\
\hline
\end{tabular}




\section{$\underline{\text { References }}$}

Attardi, L. D., \& Donehower, L. A. (2005). Probing p53 biological functions through the use of genetically engineered mouse models. Mutat Res, 576(1-2), 4-21. doi:10.1016/j.mrfmmm.2004.08.022

Baud, M. G. J., Bauer, M. R., Verduci, L., Dingler, F. A., Patel, K. J., Horil Roy, D., . . Fersht, A. R. (2018). Aminobenzothiazole derivatives stabilize the thermolabile p53 cancer mutant Y220C and show anticancer activity in p53-Y220C cell lines. Eur J Med Chem, 152, 101-114. doi:10.1016/j.ejmech.2018.04.035

Bauer, M. R., Kramer, A., Settanni, G., Jones, R. N., Ni, X., Khan Tareque, R., . . Joerger, A. C. (2020). Targeting Cavity-Creating p53 Cancer Mutations with Small-Molecule Stabilizers: the Y220X Paradigm. ACS Chem Biol, 15(3), 657-668. doi:10.1021/acschembio.9b00748

Berghmans, S., Murphey, R. D., Wienholds, E., Neuberg, D., Kutok, J. L., Fletcher, C. D., . . Look, A. T. (2005). tp53 mutant zebrafish develop malignant peripheral nerve sheath tumors. Proc Natl Acad Sci $U$ $S$ A, 102(2), 407-412. doi:10.1073/pnas.0406252102

Blackburn, J. S., Liu, S., Wilder, J. L., Dobrinski, K. P., Lobbardi, R., Moore, F. E., . . Langenau, D. M. (2014). Clonal evolution enhances leukemia-propagating cell frequency in T cell acute lymphoblastic leukemia through Akt/mTORC1 pathway activation. Cancer Cell, 25(3), 366-378. doi:10.1016/j.ccr.2014.01.032

Blanden, A. R., Yu, X., Blayney, A. J., Demas, C., Ha, J. H., Liu, Y., . . . Loh, S. N. (2020). Zinc shapes the folding landscape of p53 and establishes a pathway for reactivating structurally diverse cancer mutants. Elife, 9. doi:10.7554/eLife.61487

Blanden, A. R., Yu, X., Wolfe, A. J., Gilleran, J. A., Augeri, D. J., O'Dell, R. S., . . Loh, S. N. (2015). Synthetic metallochaperone ZMC1 rescues mutant p53 conformation by transporting zinc into cells as an ionophore. Mol Pharmacol, 87(5), 825-831. doi:10.1124/mol.114.097550

Casey, D. L., Wexler, L. H., Pitter, K. L., Samstein, R. M., Slotkin, E. K., \& Wolden, S. L. (2020). Genomic Determinants of Clinical Outcomes in Rhabdomyosarcoma. Clin Cancer Res, 26(5), 1135-1140. doi:10.1158/1078-0432.CCR-19-2631

Castresana, J. S., Rubio, M. P., Gomez, L., Kreicbergs, A., Zetterberg, A., \& Barrios, C. (1995). Detection of TP53 gene mutations in human sarcomas. Eur J Cancer, 31A(5), 735-738. doi:10.1016/09598049(95)00121-X

Chen, E. Y., DeRan, M. T., Ignatius, M. S., Grandinetti, K. B., Clagg, R., McCarthy, K. M., . . Langenau, D. M. (2014). Glycogen synthase kinase 3 inhibitors induce the canonical WNT/beta-catenin pathway to suppress growth and self-renewal in embryonal rhabdomyosarcoma. Proc Natl Acad Sci U S A, 111(14), 5349-5354. doi:10.1073/pnas.1317731111

Chen, X., Bahrami, A., Pappo, A., Easton, J., Dalton, J., Hedlund, E., . . St. Jude Children's Research Hospital-Washington University Pediatric Cancer Genome, P. (2014). Recurrent somatic structural variations contribute to tumorigenesis in pediatric osteosarcoma. Cell Rep, 7(1), 104-112. doi:10.1016/j.celrep.2014.03.003

Chen, X., Stewart, E., Shelat, A. A., Qu, C., Bahrami, A., Hatley, M., . . St. Jude Children's Research Hospital-Washington University Pediatric Cancer Genome, P. (2013). Targeting oxidative stress in embryonal rhabdomyosarcoma. Cancer Cell, 24(6), 710-724. doi:10.1016/j.ccr.2013.11.002

Di Como, C. J., \& Prives, C. (1998). Human tumor-derived p53 proteins exhibit binding site selectivity and temperature sensitivity for transactivation in a yeast-based assay. Oncogene, 16(19), 2527-2539. doi:10.1038/sj.onc.1202041

Drummond, C. J., Hanna, J. A., Garcia, M. R., Devine, D. J., Heyrana, A. J., Finkelstein, D., . . Hatley, M. E. (2018). Hedgehog Pathway Drives Fusion-Negative Rhabdomyosarcoma Initiated From Non-myogenic Endothelial Progenitors. Cancer Cell, 33(1), 108-124 e105. doi:10.1016/j.ccell.2017.12.001

el-Deiry, W. S., Tokino, T., Velculescu, V. E., Levy, D. B., Parsons, R., Trent, J. M., . . Vogelstein, B. (1993). WAF1, a potential mediator of p53 tumor suppression. Cell, 75(4), 817-825. doi:10.1016/00928674(93)90500-p

Garcia, P. B., \& Attardi, L. D. (2014). Illuminating p53 function in cancer with genetically engineered mouse models. Semin Cell Dev Biol, 27, 74-85. doi:10.1016/j.semcdb.2013.12.014 
Gibson, A. A., Harwood, F. G., Tillman, D. M., \& Houghton, J. A. (1998). Selective sensitization to DNAdamaging agents in a human rhabdomyosarcoma cell line with inducible wild-type p53 overexpression. Clin Cancer Res, 4(1), 145-152. Retrieved from https://www.ncbi.nlm.nih.gov/pubmed/9516963

Grobner, S. N., Worst, B. C., Weischenfeldt, J., Buchhalter, I., Kleinheinz, K., Rudneva, V. A., . . . Project, I. M.-S. (2018). Author Correction: The landscape of genomic alterations across childhood cancers. Nature, 559(7714), E10. doi:10.1038/s41586-018-0167-2

Guha, T., \& Malkin, D. (2017). Inherited TP53 Mutations and the Li-Fraumeni Syndrome. Cold Spring Harb Perspect Med, 7(4). doi:10.1101/cshperspect.a026187

Hatley, M. E., Tang, W., Garcia, M. R., Finkelstein, D., Millay, D. P., Liu, N., . . Olson, E. N. (2012). A mouse model of rhabdomyosarcoma originating from the adipocyte lineage. Cancer Cell, 22(4), 536-546. doi:10.1016/j.ccr.2012.09.004

Hayes, M. N., McCarthy, K., Jin, A., Oliveira, M. L., Iyer, S., Garcia, S. P., . . Langenau, D. M. (2018). Vangl2/RhoA Signaling Pathway Regulates Stem Cell Self-Renewal Programs and Growth in Rhabdomyosarcoma. Cell Stem Cell, 22(3), 414-427 e416. doi:10.1016/j.stem.2018.02.002

Hoffman-Luca, C. G., Yang, C. Y., Lu, J., Ziazadeh, D., McEachern, D., Debussche, L., \& Wang, S. (2015). Significant Differences in the Development of Acquired Resistance to the MDM2 Inhibitor SAR405838 between In Vitro and In Vivo Drug Treatment. PLoS One, 10(6), e0128807. doi:10.1371/journal.pone.0128807

Ignatius, M. S., Chen, E., Elpek, N. M., Fuller, A. Z., Tenente, I. M., Clagg, R., . . Langenau, D. M. (2012). In vivo imaging of tumor-propagating cells, regional tumor heterogeneity, and dynamic cell movements in embryonal rhabdomyosarcoma. Cancer Cell, 21(5), 680-693. doi:10.1016/j.ccr.2012.03.043

Ignatius, M. S., Hayes, M. N., Lobbardi, R., Chen, E. Y., McCarthy, K. M., Sreenivas, P., . . Langenau, D. M. (2017). The NOTCH1/SNAIL1/MEF2C Pathway Regulates Growth and Self-Renewal in Embryonal Rhabdomyosarcoma. Cell Rep, 19(11), 2304-2318. doi:10.1016/j.celrep.2017.05.061

Ignatius, M. S., Hayes, M. N., Moore, F. E., Tang, Q., Garcia, S. P., Blackburn, P. R., . . Langenau, D. M. (2018). tp53 deficiency causes a wide tumor spectrum and increases embryonal rhabdomyosarcoma metastasis in zebrafish. Elife, 7. doi:10.7554/eLife.37202

Kashi, V. P., Hatley, M. E., \& Galindo, R. L. (2015). Probing for a deeper understanding of rhabdomyosarcoma: insights from complementary model systems. Nat Rev Cancer, 15(7), 426-439. doi:10.1038/nrc3961

Kastenhuber, E. R., \& Lowe, S. W. (2017). Putting p53 in Context. Cell, 170(6), 1062-1078. doi:10.1016/j.cell.2017.08.028

Kato, S., Han, S. Y., Liu, W., Otsuka, K., Shibata, H., Kanamaru, R., \& Ishioka, C. (2003). Understanding the function-structure and function-mutation relationships of p53 tumor suppressor protein by highresolution missense mutation analysis. Proc Natl Acad Sci U S A, 100(14), 8424-8429. doi:10.1073/pnas.1431692100

Ko, L. J., \& Prives, C. (1996). p53: puzzle and paradigm. Genes Dev, 10(9), 1054-1072. doi:10.1101/gad.10.9.1054

Langenau, D. M., Keefe, M. D., Storer, N. Y., Guyon, J. R., Kutok, J. L., Le, X., . . Zon, L. I. (2007). Effects of RAS on the genesis of embryonal rhabdomyosarcoma. Genes Dev, 21(11), 1382-1395. doi:10.1101/gad.1545007

Langenau, D. M., Keefe, M. D., Storer, N. Y., Jette, C. A., Smith, A. C., Ceol, C. J., . . Zon, L. I. (2008). Coinjection strategies to modify radiation sensitivity and tumor initiation in transgenic Zebrafish. Oncogene, 27(30), 4242-4248. doi:10.1038/onc.2008.56

Levine, A. J., Momand, J., \& Finlay, C. A. (1991). The p53 tumour suppressor gene. Nature, 351(6326), 453456. doi: $10.1038 / 351453 a 0$

Lobbardi, R., Pinder, J., Martinez-Pastor, B., Theodorou, M., Blackburn, J. S., Abraham, B. J., ... Langenau, D. M. (2017). TOX Regulates Growth, DNA Repair, and Genomic Instability in T-cell Acute Lymphoblastic Leukemia. Cancer Discov, 7(11), 1336-1353. doi:10.1158/2159-8290.CD-17-0267

Lozano, G. (2010). Mouse models of p53 functions. Cold Spring Harb Perspect Biol, 2(4), a001115. doi:10.1101/cshperspect.a001115

Malkin, D. (2011). Li-fraumeni syndrome. Genes Cancer, 2(4), 475-484. doi:10.1177/1947601911413466

Mao, J., Ligon, K. L., Rakhlin, E. Y., Thayer, S. P., Bronson, R. T., Rowitch, D., \& McMahon, A. P. (2006). A novel somatic mouse model to survey tumorigenic potential applied to the Hedgehog pathway. Cancer Res, 66(20), 10171-10178. doi:10.1158/0008-5472.CAN-06-0657 
Marcellus, R. C., Teodoro, J. G., Charbonneau, R., Shore, G. C., \& Branton, P. E. (1996). Expression of p53 in Saos-2 osteosarcoma cells induces apoptosis which can be inhibited by Bcl-2 or the adenovirus E1B55 kDa protein. Cell Growth Differ, 7(12), 1643-1650. Retrieved from https://www.ncbi.nlm.nih.gov/pubmed/8959332

Michalarea, V., Calcasola, M., Cane, P., Tobal, K., Izatt, L., \& Spicer, J. (2014). EGFR-mutated lung cancer in Li-Fraumeni syndrome. Lung Cancer, 85(3), 485-487. doi:10.1016/j.lungcan.2014.06.017

Muller, P. A., \& Vousden, K. H. (2014). Mutant p53 in cancer: new functions and therapeutic opportunities. Cancer Cell, 25(3), 304-317. doi:10.1016/j.ccr.2014.01.021

Natan, E., Baloglu, C., Pagel, K., Freund, S. M., Morgner, N., Robinson, C. V., . . Joerger, A. C. (2011). Interaction of the p53 DNA-binding domain with its n-terminal extension modulates the stability of the p53 tetramer. J Mol Biol, 409(3), 358-368. doi:10.1016/j.jmb.2011.03.047

Olive, K. P., Tuveson, D. A., Ruhe, Z. C., Yin, B., Willis, N. A., Bronson, R. T., . . Jacks, T. (2004). Mutant p53 gain of function in two mouse models of Li-Fraumeni syndrome. Cell, 119(6), 847-860. doi:10.1016/j.cell.2004.11.004

Overholtzer, M., Rao, P. H., Favis, R., Lu, X. Y., Elowitz, M. B., Barany, F., . . Levine, A. J. (2003). The presence of p53 mutations in human osteosarcomas correlates with high levels of genomic instability. Proc Natl Acad Sci U S A, 100(20), 11547-11552. doi:10.1073/pnas.1934852100

Petitjean, A., Achatz, M. I., Borresen-Dale, A. L., Hainaut, P., \& Olivier, M. (2007). TP53 mutations in human cancers: functional selection and impact on cancer prognosis and outcomes. Oncogene, 26(15), 21572165. doi:10.1038/sj.onc. 1210302

Pfister, N. T., \& Prives, C. (2017). Transcriptional Regulation by Wild-Type and Cancer-Related Mutant Forms of p53. Cold Spring Harb Perspect Med, 7(2). doi:10.1101/cshperspect.a026054

Piccinin, S., Tonin, E., Sessa, S., Demontis, S., Rossi, S., Pecciarini, L., . . Maestro, R. (2012). A "twist box" code of p53 inactivation: twist box: p53 interaction promotes p53 degradation. Cancer Cell, 22(3), 404415. doi:10.1016/j.ccr.2012.08.003

Satheesha, S., Manzella, G., Bovay, A., Casanova, E. A., Bode, P. K., Belle, R., . . Schafer, B. W. (2016). Targeting hedgehog signaling reduces self-renewal in embryonal rhabdomyosarcoma. Oncogene, 35(16), 2020-2030. doi:10.1038/onc.2015.267

Schwede, T., Kopp, J., Guex, N., \& Peitsch, M. C. (2003). SWISS-MODEL: An automated protein homologymodeling server. Nucleic Acids Res, 31(13), 3381-3385. doi:10.1093/nar/gkg520

Seki, M., Nishimura, R., Yoshida, K., Shimamura, T., Shiraishi, Y., Sato, Y., . . Takita, J. (2015). Integrated genetic and epigenetic analysis defines novel molecular subgroups in rhabdomyosarcoma. Nat Commun, 6, 7557. doi:10.1038/ncomms8557

Shern, J. F., Chen, L., Chmielecki, J., Wei, J. S., Patidar, R., Rosenberg, M., . . Khan, J. (2014). Comprehensive genomic analysis of rhabdomyosarcoma reveals a landscape of alterations affecting a common genetic axis in fusion-positive and fusion-negative tumors. Cancer Discov, 4(2), 216-231. doi:10.1158/2159-8290.CD-13-0639

Szymczak-Workman, A. L., Vignali, K. M., \& Vignali, D. A. (2012). Generation of 2A-linked multicistronic cassettes by recombinant PCR. Cold Spring Harb Protoc, 2012(2), 251-254. doi:10.1101/pdb.prot067884

Taylor, A. C., Shu, L., Danks, M. K., Poquette, C. A., Shetty, S., Thayer, M. J., . . Harris, L. C. (2000). P53 mutation and MDM2 amplification frequency in pediatric rhabdomyosarcoma tumors and cell lines. Med Pediatr Oncol, 35(2), 96-103. doi:10.1002/1096-911x(200008)35:2<96::aid-mpo2>3.0.co;2-z

Tenente, I. M., Hayes, M. N., Ignatius, M. S., McCarthy, K., Yohe, M., Sindiri, S., . . Langenau, D. M. (2017). Myogenic regulatory transcription factors regulate growth in rhabdomyosarcoma. Elife, 6. doi:10.7554/eLife.19214

Tirode, F., Surdez, D., Ma, X., Parker, M., Le Deley, M. C., Bahrami, A., . . the International Cancer Genome, C. (2014). Genomic landscape of Ewing sarcoma defines an aggressive subtype with co-association of STAG2 and TP53 mutations. Cancer Discov, 4(11), 1342-1353. doi:10.1158/2159-8290.CD-14-0622

Wang, G., \& Fersht, A. R. (2017). Multisite aggregation of p53 and implications for drug rescue. Proc Natl Acad Sci U S A, 114(13), E2634-E2643. doi:10.1073/pnas.1700308114

Waterhouse, A., Bertoni, M., Bienert, S., Studer, G., Tauriello, G., Gumienny, R., . . Schwede, T. (2018). SWISS-MODEL: homology modelling of protein structures and complexes. Nucleic Acids Res, 46(W1), W296-W303. doi:10.1093/nar/gky427 
bioRxiv preprint doi: https://doi.org/10.1101/2021.04.21.440757; this version posted April 22, 2021. The copyright holder for this preprint (which was not certified by peer review) is the author/funder, who has granted bioRxiv a license to display the preprint in perpetuity. It is made available under aCC-BY 4.0 International license.

White, R., Rose, K., \& Zon, L. (2013). Zebrafish cancer: the state of the art and the path forward. Nat Rev Cancer, 13(9), 624-636. doi:10.1038/nrc3589

Yu, X., Vazquez, A., Levine, A. J., \& Carpizo, D. R. (2012). Allele-specific p53 mutant reactivation. Cancer Cell, 21(5), 614-625. doi:10.1016/j.ccr.2012.03.042 